\title{
Superconductor Application to the Magnetic Fusion Devices for the Steady-State Plasma Confinement Achievement
}

\author{
Yeong-Kook Oh*, Keeman Kim, Kap-Rai Park and Young-Min Park \\ National Fusion Research Institute (NFRI), Daejeon \\ Republic of Korea
}

\section{Introduction}

\subsection{History of the superconductor application into fusion devices}

The exploitation of the new energy source is necessary in upcoming century due to the rapid increasing of energy consumption and the shortage of the fossil energy sources in the world. There have been a lot of scientific and engineering efforts to make realization of the fusion energy production as a clean and limitless energy source to the mankind. The fusion energy has great advantages in the points of the energy density and the amount of resources, and it is a dominant energy source in the universe like the sun and stars. To achieve a reliable fusion reaction, a good confinement technology is required to overcome the repulsive force between nucleuses of light atoms like hydrogen isotopes as shown in Fig. 1. Among the confinement technologies two kinds of methods are dominant in the fusion researches. The one is the inertial confinement which focusing the high power laser beams in to the small size fuel pellet. The other is the magnetic confinement which confining the fuel gas in plasma state in vacuum by applying the high magnetic fields.

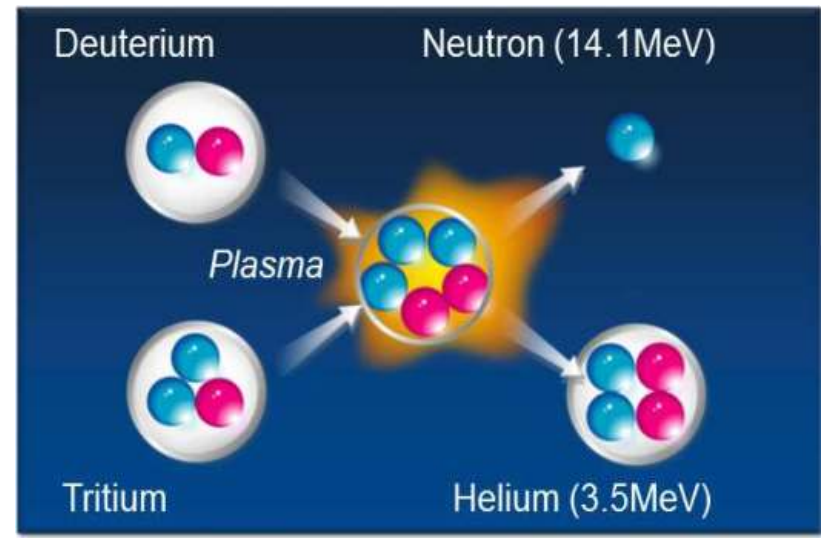

Fig. 1. A representative fusion reaction. The confinement of hydrogen isotopes, deuterium and tritium produces neutron and helium atom with total energy of about $17.6 \mathrm{MeV}$ 
The first use of superconducting coils in experimental fusion devices dates back to the midseventies. Three main kinds of fusion devices have been studied for plasma confinement using superconducting coils: the mirror machines, the stellerators and the tokamaks. In the initial stage, the application of the superconductor was only for DC or slowly changing in magnetic field like toroidal field (TF) coils in tokamaks or stellerator magnets. The efforts of the last 10 years concentrated on the tokamaks with limited stellerator. The stored magnetic energy and the size of the superconducting fusion devices grew by up to three orders of magnitude in 30 years, from the $20 \mathrm{MJ}$ in the first superconducting tokamak, T-7 to the international thermonuclear experimental reactor (ITER).

There has been a lot of development in the superconducting magnet technologies for the application to the fusion devices, in the superconducting technologies related with the cooling, the superconductor, and the operation mode (Bruzzone, P., 2010). In the cooling method to keep cold a superconducting magnet, the liquid helium bath cooling was the only option in the very first applications. As alternative cooling options, superfluid helium bath cooling at $1.8 \mathrm{~K}$ was applied into Tore-Supra in France and forced-flow supercritical helium cooling at about $4.5 \mathrm{~K}$ was applied into the recent tokamaks (SST-1, EAST, KSTAR, JT60SA, and ITER) and stellerators (LHD and W7-X). The requirement of mechanical stiffness and reliability of the high voltage electric insulation has ruled out the pool cooling option from the fusion devices of present and future generations. In large devices, with total mass flow rate in the range of several $\mathrm{kg} / \mathrm{s}$, the forced flow cooling of supercritical helium is assisted by cold circulation pumps and heat exchangers. Extensive activities on conductor development led to a large variety of $\mathrm{NbTi}$ and $\mathrm{Nb}_{3} \mathrm{Sn}$ conductor design. With increasing coil size and stored energy, the operating current must be increased to keep low values in the number of turns and the inductance. At operating current over $5 \mathrm{kA}$, the single multi-filamentary composite is no longer an option because of the ac loss and stability issues. Cable-in-conduit conductor (CICC), both $\mathrm{NbTi}$ and $\mathrm{Nb}_{3} \mathrm{Sn}$, became a dominant option in superconductor for large current over $10 \mathrm{kA}$ in fusion device. The advantages of the CICC are direct contact of the conductor with forced-flow helium, structural rigidity is guaranteed by steel jacket surrounding the cable, and the electric insulation by the turn insulation and vacuum pressure impregnation (VPI). In the operation mode of the superconductor, only the DC coils were considered an application target for superconductors. The T7, T15, and Tore Supra tokamaks had copper coil for plasma start-up and shaping. By appearance of the CICC, the superconductor application was expanded into the fast varying central solenoid (CS) or poloidal field (PF) coils in the recent tokamaks, the EAST (Wu, S. et al., 2002), KSTAR (Lee, G.S. et al., 2001), JT-60SA (Yoshida, K. et al., 2008), and ITER (Mitchell, N., 2003). Figure 2 shows the peak field and operation current of the superconducting coils in the fusion devices. NbTi conductor is used in the coils operated at lower field less than $7 \mathrm{~T}$, except Tore-Supra device which is operated at $9 \mathrm{~T}$ by cooling with $1.8 \mathrm{~K}$ superfluid helium. $\mathrm{Nb}_{3} \mathrm{Sn}$ conductor is used in the coils operated higher field. KSTAR TF conductor is operated at $35 \mathrm{kA}$ and is the highest current carrying conductor before ITER operation.

\subsection{A recent superconducting tokamak, KSTAR}

The operation of the KSTAR device has been started after the integrated commissioning of all superconducting magnets in 2008 (Oh, Y.K. et al., 2009). The mission of the KSTAR project is to develop a steady-state-capable advanced superconducting tokamak, and to establish a scientific and technological basis for an attractive fusion reactor (Lee, G.S. et al., 2001). Figure 3 shows the design of the KSTAR device comparing with ITER device. The 
KSTAR device has lots of technical similarities with the ITER device such as using the same material of superconducting conductor, $\mathrm{Nb}_{3} \mathrm{Sn} \mathrm{CICC}$, and targeting the steady-state high performance plasma confinement over 300s. KSTAR adopted the most outstanding research results from the present devices and will exploit high performance steady-state operation which will provide the core technology for ITER and for future reactors. The designed parameters of KSTAR, as shown in Table 1, are major radius $1.8 \mathrm{~m}$, minor radius $0.5 \mathrm{~m}$, toroidal field $3.5 \mathrm{~T}$, and plasma current $2 \mathrm{MA}$ for $300 \mathrm{~s}$. The specific features in the KSTAR design are full superconducting magnets, passive stabilizers and segmented 3-dimentional in-vessel coils for the fast plasma stabilizations, various kinds of heating and current drive systems for the high-beta and non-inductive current drive, and strong plasma shaping for double-null or single-null configurations.

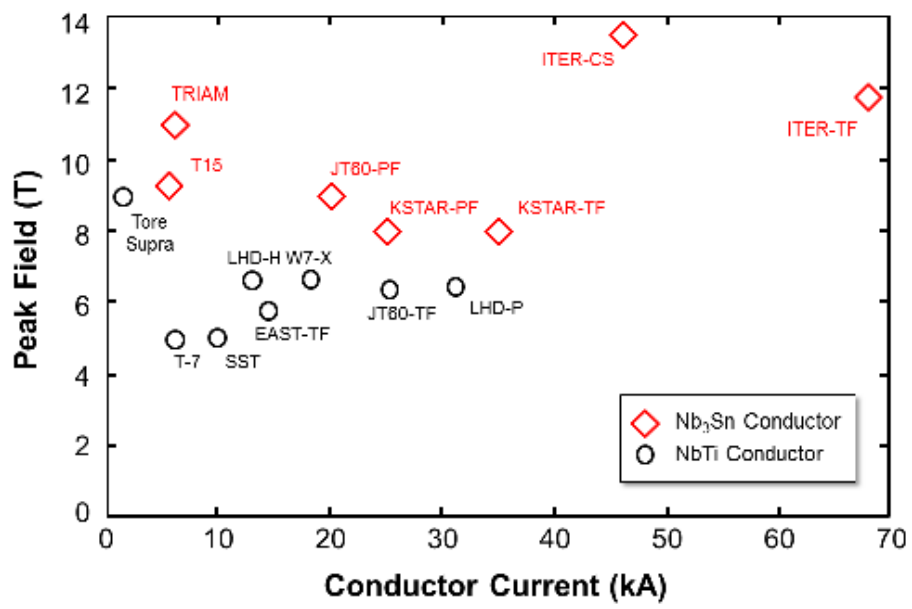

Fig. 2. The progress of the superconductor application in the magnetic fusion devices. The comparison of the operating current and peak field of the conductors in the worldwide superconducting fusion devices.

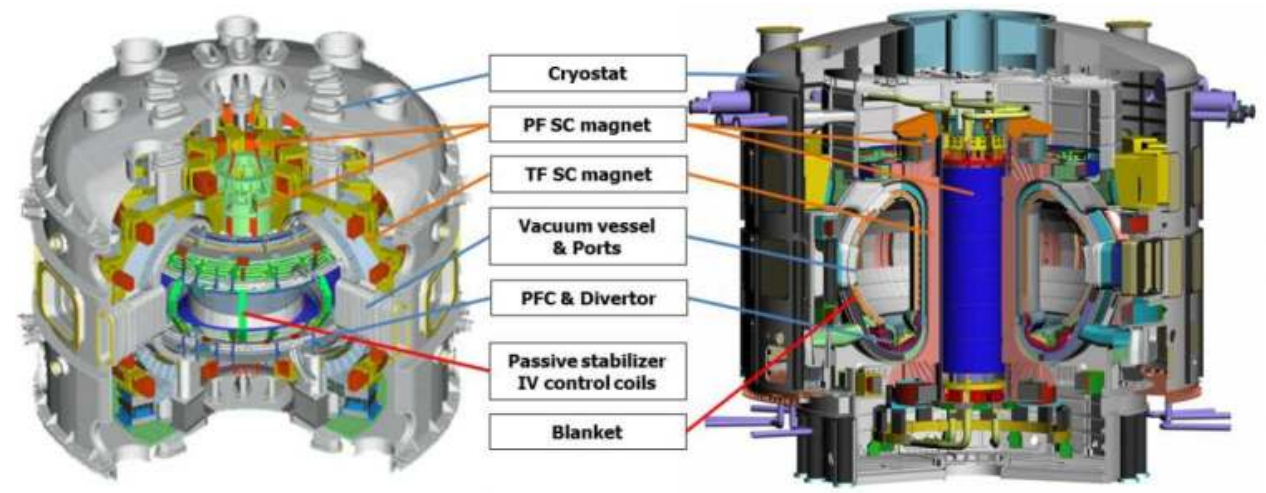

Fig. 3. The design comparison between KSTAR and ITER devices. The dimension is much different but the components and their engineering are similar together. 


\begin{tabular}{l|c|c}
\hline & KSTAR & ITER \\
\hline Major radius, R0 [m] & 1.8 & 6.2 \\
Minor radius, a [m] & 0.5 & 2.0 \\
Plasma current, Ip [MA] & 2.0 & $15(17)$ \\
Elongation, $\kappa$ & 2.0 & 1.7 \\
Triangularity, $\delta$ & 0.8 & 0.33 \\
Toroidal field, $\mathrm{B}_{0}[\mathrm{~T}]$ & 3.5 & 5.3 \\
Pulse length [s] & 300 & 400 \\
Plasma volume [m $\left.{ }^{3}\right]$ & 17.8 & 830 \\
Plasma cross section [m²] & 1.6 & 22 \\
Plasma shape & $\mathrm{DN}, \mathrm{SN}$ & $\mathrm{SN}$ \\
Normalized beta & 5.0 & $1.8(2.5)$ \\
Plasma fuel & $\mathrm{H}, \mathrm{D}$ & $\mathrm{H}, \mathrm{D}, \mathrm{T}$ \\
Superconductor & $\mathrm{Nb}_{3} \mathrm{Sn}, \mathrm{NbTi}$ & $\mathrm{Nb}_{3} \mathrm{Sn}, \mathrm{NbTi}$ \\
Auxiliary heating /CD [MW] & 28 & $73(110)$ \\
\hline
\end{tabular}

Table 1. Key design parameters of the KSTAR and ITER devices.

In this chapter, the generals about the superconducting technology used in the magnetic fusion devices are described with an example of the KSTAR device, which is the most recently constructed superconducting fusion device and is in operation. The development of a CICC conductor for the fusion application is described in section 2, and Superconducting magnet fabrication and test is in section 3, magnet assembly and interfaces are in section 4, integrated commissioning of the superconducting tokamak is in section 5, and the plasma experiments and consideration of the magnet operation are in section 6 .

\section{Cable-in-conduit conductor development}

Most of the superconducting coils in KSTAR are made of $\mathrm{Nb}_{3} \mathrm{Sn}$ superconductor with Incoloy908 jacket, but large PF coils (PF6-7), which operated at lower field, are made of NbTi superconductor with STS316LN jacket.

Usually TF magnet operated in static mode but PF magnet in pulsed mode. So in ITER design, two different type of superconductor was considered. The superconductor for the TF magnet should satisfy the HP-I criteria that is high current density capacity over $750 \mathrm{~A} / \mathrm{mm}^{2}$ at $12 \mathrm{~T}, 4.2 \mathrm{~K}$ and the superconductor for PF magnet should satisfy the HP-II criteria that is low hysteresis loss generation less than $250 \mathrm{~mJ} / \mathrm{cc}$ at of $3 \mathrm{~T}$ cycle. But in KSTAR a new superconductor has been developed to satisfy both criteria simultaneously (HP-III), and constructed TF and PF magnet using same type of superconductor. The cross sectional view of the $\mathrm{Nb}_{3} \mathrm{Sn}$ superconductor strand is seen in Fig. 4(a). In the superconductor configuration, the number $\mathrm{Nb}_{3} \mathrm{Sn}$ filaments are over 3,000 to get the current density and low hysteresis loss. To reduce the ac loss at the fast varying field environment, each strand is coated with high resistance chrome with a thickness of $1 \pm 0.2 \mu \mathrm{m}$. The chrome coating is used to survive after the long period of heat treatment of the $\mathrm{Nb}_{3} \mathrm{Sn}$ coil.

Large number of strands are cabled together and overwrapped with steel jacket in the form of CICC to have structural rigidity at the large current in the range of several tens of $\mathrm{kA}$ and high field over 7 T. KSTAR CICC is shaped into square cross section with round corner as 
shown in the Fig. $4(\mathrm{~b})$. The cable patterns of the TF and PF conductors are $3 \times 3 \times 3 \times 3 \times 6$ of 486 strands and $3 \times 4 \times 5 \times 6$ of 360 strands, respectively. Two superconducting strands and one OFHC copper strand are cabled together to become a triplet in the first cabling stage. The cabling pitch of the TF and PF conductors are 40-73-157-227-355 $\mathrm{mm}$ and 40-80-145-237 mm, respectively. At the final stage of cable fabrication, the cable is wrapped with a thin stainless-steel strip, $30 \mathrm{~mm}$ wide and $0.05 \mathrm{~mm}$ thick, with $20 \%$ overlap at each side. The selection of the jacket material is also important factor deciding the $\mathrm{Nb}_{3} \mathrm{Sn}$ conductor performance, because the operating current limit is decreased according to the strain applied to the conductor and the strain is mainly come from the difference in coefficient of the thermal expansion (COE) between superconductor and jacket material. In KSTAR, Incoloy 908 is selected as the jacket material for $\mathrm{Nb}_{3} \mathrm{Sn}$ conductor.

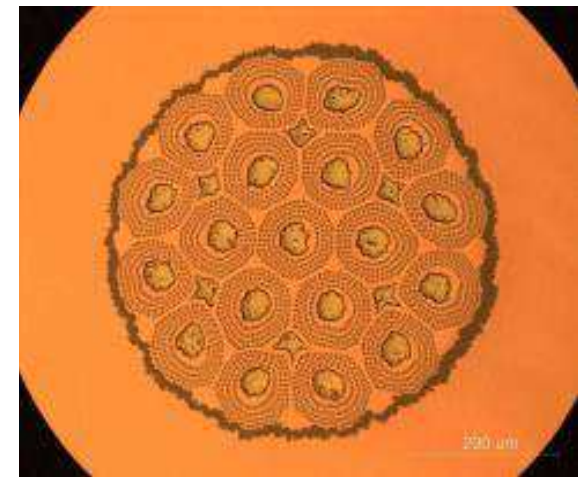

(a)

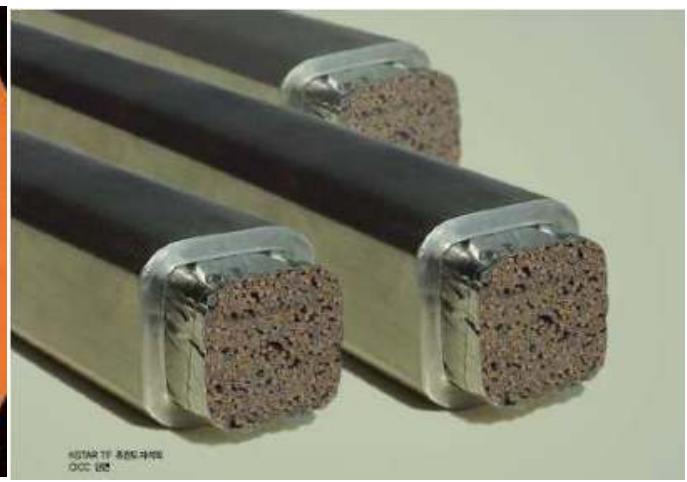

(b)

Fig. 4. The picture of the KSTAR superconductor. Cross sectional view of the $\mathrm{Nb}_{3} \mathrm{Sn}$ superconductor (a) and CICC (b).

The length of the conductor is also an important factor in the magnet design. If a longer CICC is available then the number of internal joint could be reduced or excluded. It could guarantee more stable operation of the magnet because lots of troubles come from the joints. In KSTAR, tube-mill process was developed to produce long CICC with various lengths up to $1.8 \mathrm{~km}$ to exclude the internal joint. The tube-mill process consists of forming, welding, sizing and squaring procedures. A strip is wrapped around the superconducting cable through a series of progressive roller dies and welded using gas tungsten arc welding (GTAW). The welded sheath is cooled immediately by water and the face-bead of the weld is ground by a bead grinding machine. The shape of the welding back-bead is controlled to be smooth not to damage the superconducting cable. Then, the conductors are formed to the final dimension of the CICC.

The leak tightness is an important qualification of the conductor, because the helium leak from the conductor could hinder the cooling the magnet to the cryogenic temperature due to the increased convective heat transfer. The CICC fabricated by tube-mill process have more possibility of the leak due to the longitudinal welding line. Leak detection of CICC spool was performed in the water chamber by pressurizing the CICC spool with helium at about 50 bars as shown in Fig. 5(a). The locations of the leak were identified by detecting bubbles generated in the water chamber. After machining the leak point with a special grinder, 
repairing welding was performed carefully with high purity helium supplying inside the CICC as shown in Fig. 5(b). Leak tightness of each CICC spool was guaranteed by repeating the leak detection and repairing process (Lim, B.S. et al., 2005).

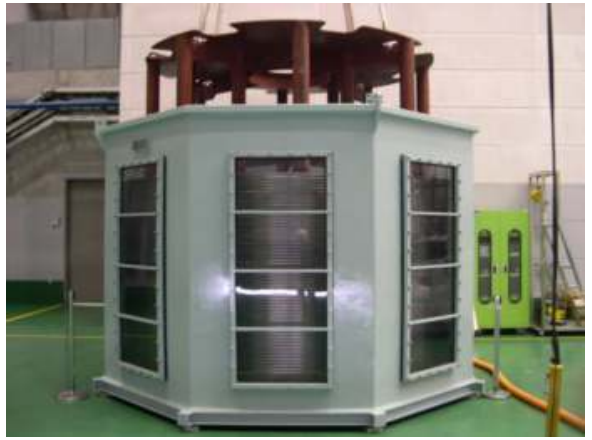

(a)

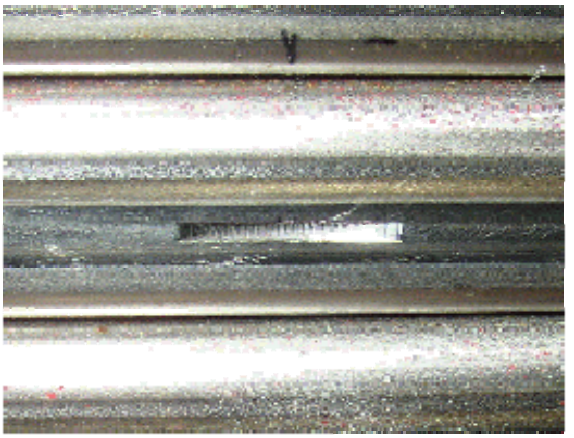

(b)

Fig. 5. Picture of qualification of the KSTAR CICC. The leak detection of the CICC spool in the water chamber by pressurizing the conductor with helium gas (a) and grinding the leak point for the repair welding $(b)$.

\section{Superconducting magnet fabrication and qualification test}

\subsection{Fabrication procedure of superconducting magnet}

The superconducting magnet system of the KSTAR device consists of 16 TF coils and 14 PF coils as shown in Fig. 6 . The design parameters of the TF coils are listed in table 2. The TF magnet system provides a magnetic field of $3.5 \mathrm{~T}$ at the plasma centre, with a peak flux density at the TF coils of 7.2 T and the stored energy of $470 \mathrm{MJ}$. The nominal current of the TF coils is $35.2 \mathrm{kA}$ with all the coils connected in a series. The total cold mass of the TF magnet system is about 150 tons. The coolant used in TF coils is supercritical helium with an inlet temperature of $4.5 \mathrm{~K}$ and an inlet pressure of 5 bar. There are four cooling channels per TF coil and the design value of the total helium mass flow rate in the $16 \mathrm{TF}$ coils is $300 \mathrm{~g} / \mathrm{s}$.

The design parameters of the CS and PF coils are listed in table 3. The PF magnet system, which consists of 8 coils in the central solenoid coil system (PF1-4) and 6 outer PF coils (PF5-7), sustains the plasma current of 2 MA for 20 s, inductively (Kim, K. et al., 2005). The designed peak currents are $25 \mathrm{kA}$ and $20 \mathrm{kA}$ for the $\mathrm{Nb}_{3} \mathrm{Sn}$ conductor and the $\mathrm{NbTi}$ conductor, respectively. The upper and lower coils of PF1, PF2 and PF7 are connected in a series inside the cryostat and the other coils can be operated separately for single-null and double-null configurations. The CS coils are segmented into four pairs of solenoid coils with different number of turns for the string shaping achievement. The total helium mass flow rate in CS and PF coils is about $300 \mathrm{~g} / \mathrm{s}$.

The coil fabrication procedure is as follows: (i) coil winding with numerical dimension control and zirconia bead grit blasting, (ii) attachment of the He feed-throughs and joint terminations, (iii) heat treatment for A15 reaction of $\mathrm{Nb}_{3} \mathrm{Sn}$ superconductor, (iv) insulation taping and ground wrapping, (v) vacuum pressure impregnation (VPI), (vi) encasing in magnet structure, and (vii) test and delivery. 


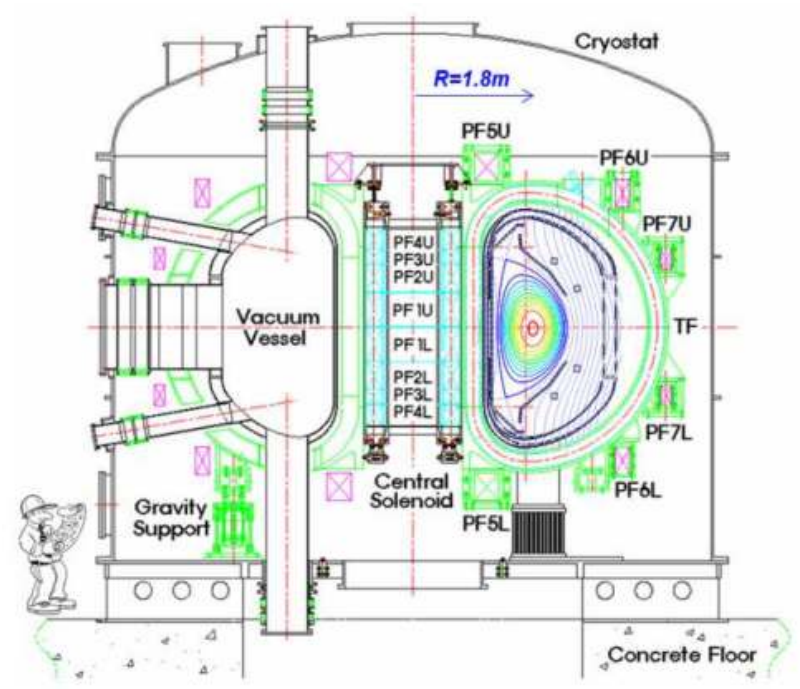

Fig. 6. The elevation view of the KSTAR device and the location of the magnets.

\begin{tabular}{l|c}
\hline Parameters & TF coils \\
\hline Superconductor & $\mathrm{Nb}_{3} \mathrm{Sn}$ \\
Conduit & Incoloy 908 \\
No. of coils & 16 \\
Toroidal field [T] & 3.5 \\
Peak field in conductor [T] & 7.2 \\
Operating current [kA] & 35.2 \\
Stored magnetic energy [Mj] & 470 \\
Centering force [MN] & 15 \\
No. of turns per coil & 56 \\
No. of pancakes & 8 \\
No. of turns per pancake & 7 \\
Conductor length per coil [m] & 610 \\
No. of cooling channels & 4 \\
Overall height [m] & 4.2 \\
Overall width [m] & 3.0 \\
\hline
\end{tabular}

Table 2. Major parameters of KSTAR TF coils. 


\begin{tabular}{l|cccc|ccc}
\hline Parameters & \multicolumn{4}{|c|}{ CS coils } & \multicolumn{3}{c}{ PF coils } \\
\hline & PF1 & PF2 & PF3 & PF4 & PF5 & PF6 & PF7 \\
\hline Superconductor & \multicolumn{4}{c}{ Nb3Sn } & Nb3Sn & NbTi \\
Conduit & \multicolumn{4}{c}{ Incoloy908 } & \multicolumn{1}{c}{ Incoloy908 } & STS316LN \\
Number of coils & 2 & 2 & 2 & 2 & 2 & 2 & 2 \\
Radial position, R [mm] & 570 & 570 & 570 & 570 & 1073 & 3090 & 3730 \\
Axial position, Z [mm] & 249 & 699 & 1005 & 1264 & 229.5 & 1920 & 980 \\
Coil width, dR [mm] & 230.5 & 230.5 & 230.5 & 230.5 & 326.3 & 206.6 & 158.8 \\
Coil height, dZ [mm] & 493.7 & 398.0 & 206.6 & 302.3 & 398.0 & 398.0 & 302.3 \\
No. turns per coil & 180 & 144 & 72 & 108 & 208 & 128 & 72 \\
No. pancakes & 20 & 16 & 8 & 12 & 16 & 16 & 12 \\
No. turns per pancake & 9 & 9 & 9 & 9 & 13 & 8 & 6 \\
CICC length / coil [m] & 663 & 537 & 283 & 410 & 1422 & 2505 & 1707 \\
No. cooling channels & 10 & 8 & 4 & 6 & 8 & 8 & 6 \\
Weight per coil [ton] & 2.34 & 1.81 & 0.96 & 1.39 & 4.8 & 8.22 & 5.65 \\
\hline
\end{tabular}

Table 3. Major parameters of KSTAR PF coils.

The continuous winding scheme is developed to exclude the internal joints. In other words, each coil is wound using a single CICC except PF6U and PF6L coils, which have one internal joint for each coil. Helium feed-throughs are attached per each double pancake. The winding stations for the TF and PF coils are shown in Fig. 7. The TF and PF1-5 coils use Nb3Sn strand and require the reaction heat treatment process. Since PF6 and PF7 coils use $\mathrm{NbTi}$ CICC, which does not require the reaction heat treatment process, the helium feedthrough attachment and Kapton and S2-glass insulation taping are carried out during the winding process (Park, K.R. et al., 2005).

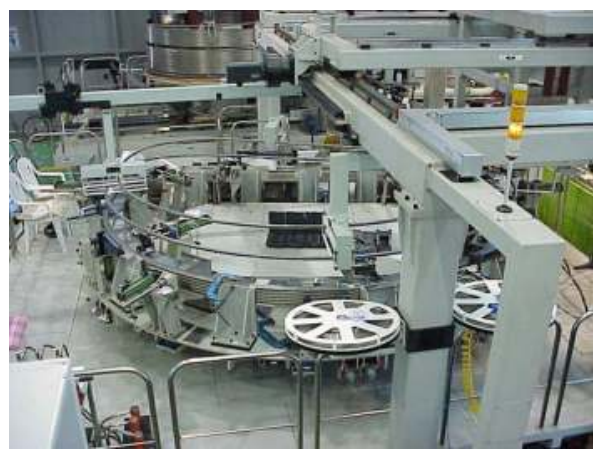

(a)

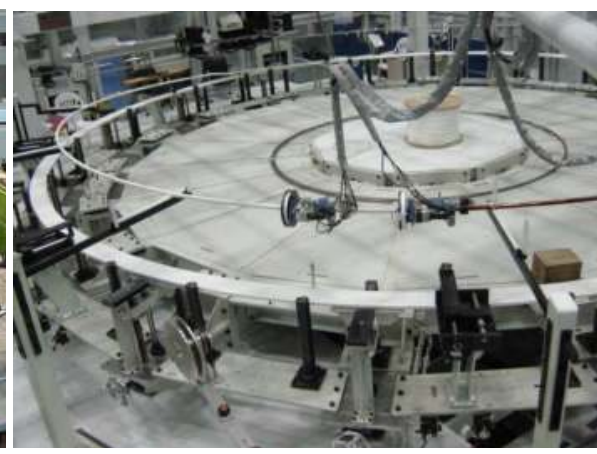

(b)

Fig. 7. The picture of coil winding stations of the TF coil (a) and PF coil (b).

After the winding, the coils are placed in a structure for the heat treatment and the preparation for heat treatment including the installation of magnet lead holding fixtures, the attachment of feed-throughs and the preparation of joint termination is carried out. In order to minimize the deformation of the winding pack during the heat treatment process, 3dimensionally machined stainless steel pieces are also installed to the empty space of layer transition area. Heat treatment is conducted in three steps of temperature: first plateau at 
$460{ }^{\circ} \mathrm{C}$ for 100 hours to remove oxygen and oil contaminants from the cable, second plateau at $570{ }^{\circ} \mathrm{C}$ for 200 hours to enhance the diffusion of $\mathrm{Sn}$ to $\mathrm{Nb}$ filament and $660{ }^{\circ} \mathrm{C}$ for 240 hours for the $\mathrm{A} 15$ reaction of $\mathrm{Nb}_{3} \mathrm{Sn}$. An Argon gas purging system is being operated during the baking process to prevent the Stress Accelerated Grain Boundary Oxidation (SAGBO) of Incoloy 908 and the oxygen content is maintained below $0.1 \mathrm{ppm}$ (Kim, K. et al., 2006).

After the heat treatment, each turn of the coil is individually separated and the CICC is insulated with $50 \%$ overlapped layers of Kapton and S2-glass tapes. S2-glass roving filler is applied at the corner of CICC to minimize the resin rich area. G10 pieces, which are shaped to fill the empty space of layer transition area, are also inserted and the coil bundle is ground insulation wrapped using S2-glass tape. As a quench detection sensor of PF1-5 coils, an externally co-wound voltage tap, which is made of a conducting polymer tape, is wound along the CICC during the turn insulation process. The co-wound voltage tap has been developed to minimize the induced voltage in quench detection line by cancellation of selfinductance. Finally vacuum pressure impregnation (VPI) is performed after placing the coil in a molding frame.

\subsection{Qualification test of superconducting magnet}

After completion of VPI, acceptance test of each coil is followed including visual and dimensional checks, Jc value, helium flow balance and high voltage insulation test (HIPOT). In the visual check and dimensional inspection, any defect or dimensional deformation is checked as shown in Fig. 8. The results show that all coils are fabricated within the allowable dimensional tolerance of $\pm 2 \mathrm{~mm}$. To qualify the heat treatment of the $\mathrm{Nb}_{3} \mathrm{Sn}$ coil, several standard sample strands are located around each coil in vacuum furnace during the heat treatment and the critical current density $\left(\mathrm{J}_{\mathrm{c}}\right)$ of the strand samples is measured to evaluate the $\mathrm{Nb}_{3} \mathrm{Sn}$ magnet performance. This qualification method is very effectively compared to the full current test at cryogenic temperature. Most of the sample showed the current density is over the design criteria of $750 \mathrm{~A} / \mathrm{mm}^{2}$ at $12 \mathrm{~T}, 4.2 \mathrm{~K}$ as shown in Fig. 9. Pressure drop of each channel is measured to assess the flow unbalance among channels during operation. From the measurement, the TF07 coil has the largest flow imbalance among channels, which was about $20 \%$. The averaged values are within approximately $10 \%$ (Park, K.R. et al., 2009).

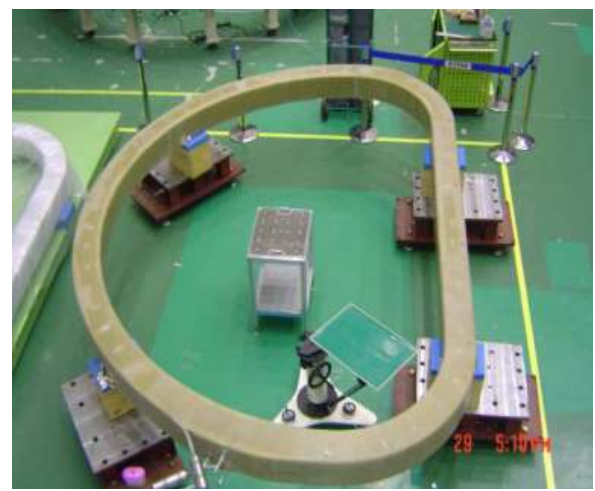

(a)

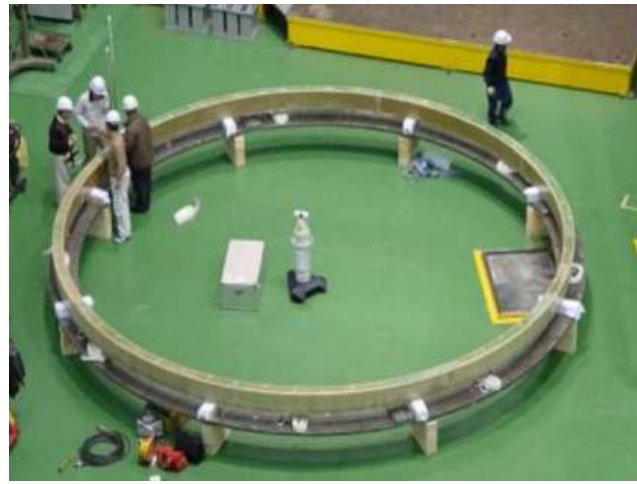

(b)

Fig. 8. Visual and dimensional inspection of the TF coil (a) and PF coils (b). 


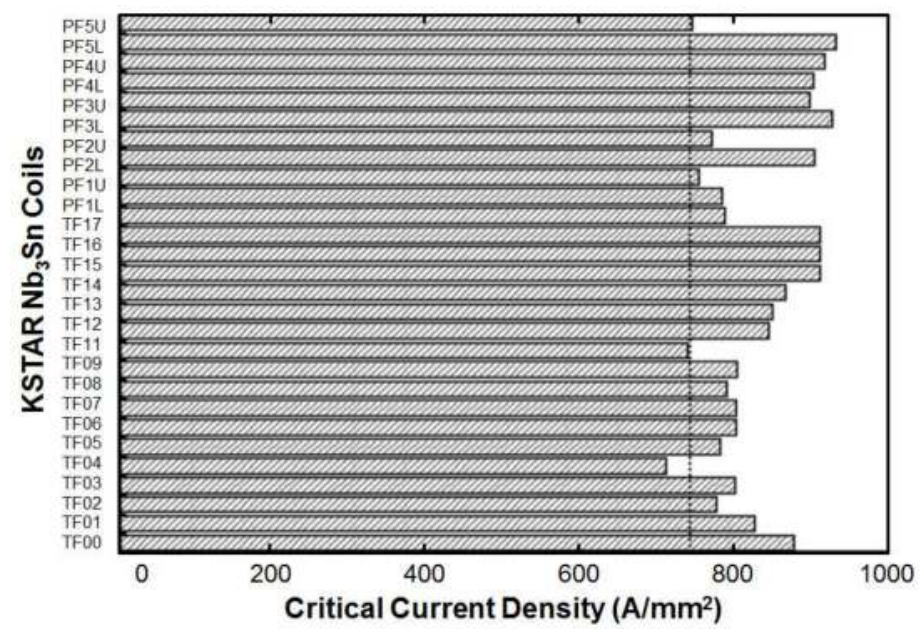

Fig. 9. The measured Jc values of the all $\mathrm{Nb}_{3} \mathrm{Sn}$ coil after heat treatment.

The HIPOT tests were carried out up to DC $15 \mathrm{kV}$ and AC $10 \mathrm{kV} @ 60 \mathrm{~Hz}$ to ensure the insulation integrity of the coils after the VPI. All coils satisfied insulation requirement of DC insulation resistance above $100 \mathrm{M} \Omega$ for the ground insulation. The impulse test was carried out to check the turn-to-turn insulation by applying the pulsed $2.4 \mathrm{kV}$ at a double pancake in a coil. The measured voltage waveforms of all pancakes were compared with each other because the waveform difference is a sign of the turn-to-turn insulation breakage. There was no observed turn-to-turn insulation failure.

Performance test of the full size TF prototype coil, TF00, and a pair of CS model coil were carried at cryogenic temperature in the test facility as shown in Fig. 10(a). The major objective of the test is to confirm the validity of the design and the fabrication process. TF00 was cooled down in 10 days within a maximum temperature variation of $50 \mathrm{~K}$. The residual resistivity ratio (RRR) of the coil was measured to be over 200. The superconducting phase transition of TF00 occurred around $18 \mathrm{~K}$. TF00 was repeatedly charged and discharged with various scenarios. The coil was operated well without any quench up to $30 \mathrm{kA}$ (Oh, Y.K. et al., 2004). The result of repeated current charge tests shows that TF00 is fabricated robustly. But the test was interrupted by the arc occurrence on one of joint due to weakness of the busline supporters and movement of the busline. We could learn from the TF00 experience that the supporting structures of the magnet system should be robust enough to sustain any kinds of force and movement. A pair of CS model coils, which has been designed for the background coil using the same conductor as KSTAR CS coil for the conductor test at 8T with a ramp rate of $3 \mathrm{~T} / \mathrm{s}$, has been installed in the test facility. The supporting structure of the main background magnetic field coil system was made of glass-fiber reinforced plastic (GFRP) material for the reduction of the eddy current during pulsed operations. CS model coils were cooled down to $5 \mathrm{~K}$ in 9 days. However, the temperature of the G10 coil support structure was approximately $30 \mathrm{~K}$ due to the low thermal conductivity. The total helium flow rate was $\sim 45 \mathrm{~g} / \mathrm{s}$ and the pressure drops $\sim 1$ bar. The coil was successfully excited to 20 $\mathrm{kA}$, where the peak field is $8.62 \mathrm{~T}$, using the DC power supply for the KSTAR TF coil. In the view point of temperature margin, the operating condition of the coil at $20 \mathrm{kA}$ is a similar 
operating condition of the KSTAR CS coil at $25 \mathrm{kA}$. The ac loss measurement was conducted with several cycles of triangular current waveform and with a long pulse sinusoidal waveform with offset to exclude nonlinear control error of the power supply at low current. However, the prototype AC power supply showed a logical error during the crossing of zero current and the AC test was performed with an offset current, which prevents the control failure of the AC power supply near zero current. The coupling time constant, nt, which was measured by changing the frequency and the amplitude of sinusoidal current as shown in Fig. 10 (b) (Oh, Y.K. et al. 2006, \& Lee, S. et al., 2006). It was less than 30 ms, which is approximately half of the design specification of $60 \mathrm{~ms}$. The result of lower coupling loss time constant have a positive expectation of the KSTAR CS coil operation and it could guarantee the fast field variance required for the plasma startup and feedback control of the KSTAR CS magnet during plasma operation. The CS model coil could be applied for the sample conductor test of ITER or for conductor R\&D for the fusion reactor (Oh, D.K. et al., 2004).

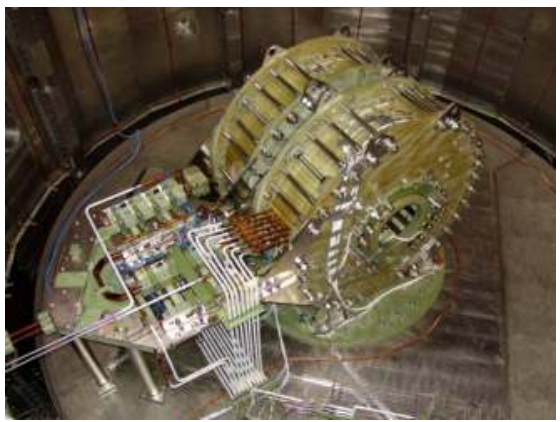

(a)

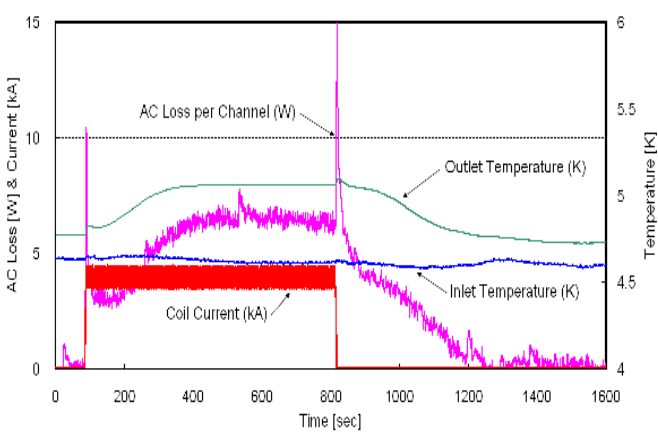

(b)

Fig. 10. CS model coil performance test. Coil installation in the vacuum cryostat (a) and Sinusoidal current waveform for ac loss measurement (b).

\section{Assembly of the magnets and interfaces}

\subsection{TF Magnet structure and assembly}

The KSTAR magnet structure consists of 16 TF structures, one CS structure, and 80 PF structures. Most of structures are made of strengthened authentic stainless steel STS316LN. Key design factors are mechanical stiffness under the large amount of Lorentz forces, electric insulation along the toroidal direction to prevent eddy current by the plasma startup and disruption, and effective cooling schemes. TF coils are under large amount of in-plane force up to $15 \mathrm{MN}$ when TF coil is charged at the nominal operating current of 35.2. And there are also out-of-plane forces up to $2.6 \mathrm{MN} / \mathrm{m}$ due to by the CS, PF, and the plasma current (Choi, C.H. et al., 2002). To sustain the electromagnetic load on the TF coils, TF structure is designed to have a wedged shape at inboard leg and to locate inter-coil structures which are strongly connected to TF case outboard legs and containing shear keys and bolts. The shape of the inter-coil structure is optimized to reduce the peak stress within allowable according to the analysis (Ahn, H.J. et al., 2002). To prevent eddy current into the toroidal direction at the plasma startup or disruptions, insulation spacer made of G-10 is attached on the entire surface 
at the gap between TF structure modules. There are 18 cooling tubes embedded inside of the structure around the coil and an additional cooling tube on the TF structure surface to limit the heat influx into the TF coil in case of the hot spot generation in the TF structure due to plasma disruption or PF coil quench. The major fabrication procedure of the TF structures are (i) fabrication of C-shaped coil case welded with inter-coil structure, (ii) fabrication of flat cover plate welded with inter-coil structure, (iii) coil encasing, (iv) final enclosure welding, (v) second vacuum pressure impregnation, (vi) final machining and delivery, and (vii) toroidal insulation attachment (Bak, J.S. et al., 2006). Figure 11 shows the final machining of TF coil case after the coil encasing. A special assembly tools has been developed to locate each magnet at the exact position. Each TF magnet is launched carefully into the 22.5 degree gap of the vacuum vessel using the loading vehicle. It is rotated in the toroidal direction and is aligned at the final position within installation error less than $1 \mathrm{~mm}$ as shown in Fig. 12 (Yang, H.L. et al., 2006). To compensate the thermal contraction of the TF magnet structure, whole TF structure was installed with a vertical offset of $5 \mathrm{~mm}$ at room temperature.

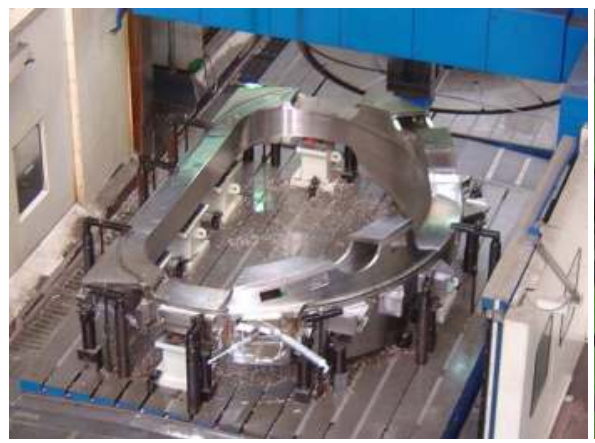

(a)

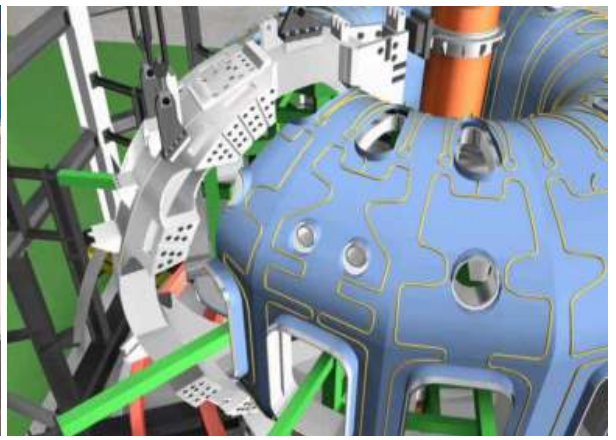

(b)

Fig. 11. TF magnet structure fabrication and assembly. Final machining after coil encasing (a) and the schematic drawing of a TF magnet installation into torus of the vacuum vessel (b).

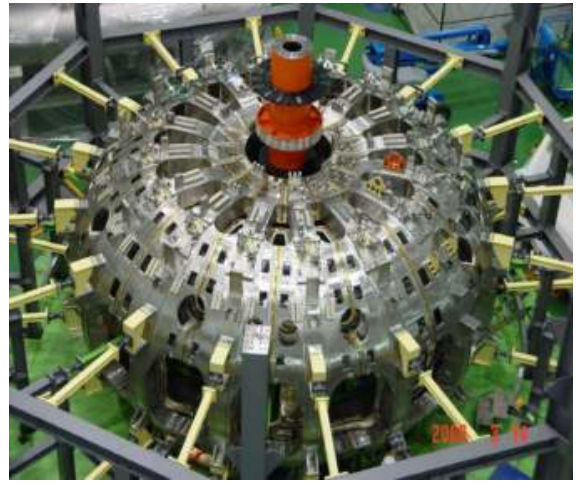

(a)

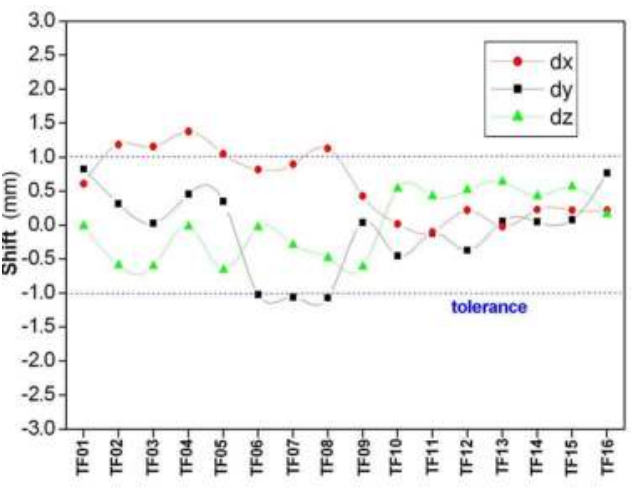

(b)

Fig. 12. TF magnet assembly qualification. Completion of whole TF magnet assembly (a) and installation error of TF magnet within $1 \mathrm{~mm}$ in the parallel shift (b). 


\subsection{CS/PF magnet structure and assembly}

The major function of the CS structure is to apply a vertical compression force on the CS coil assembly to prevent a relative motion of CS coils and to sustain the repulsive forces between CS coils during operation (Oh, Y.K. et al., 2002). The CS coils are under compressive force during the reference scenario. However, the peak separation force of $12 \mathrm{MN}$ occurs between PF1 and PF2 coils under several operation conditions, and it is called as maximum repulsive force (MRF) condition (Choi, C.H. et al., 2002; Sa, J.W. et al., 2002). The designed axial compression force is about $15 \mathrm{MN}$ at $5 \mathrm{~K}$. It will be applied partly by assembling the precompression structure at room temperature up to $13.4 \mathrm{MN}$ and partly by the thermal contraction difference between CS coils and pre-compression structure during cool down. During the subassembly of the CS magnet structire, the pre-compress structures are heated to apply the pre-compression at room temperature. When heating applied on the structure, the temperature of the epoxy-rich area of the coil also has possibility of damage due to overheat. So, the temperature of the structure was limited at $140{ }^{\circ} \mathrm{C}$, and the precompression on CS coils are estimated to be about $8 \mathrm{MN}$ at room temperature. The sub assembled CS magnet assembly is inserted into the center of KSTAR device and hang on the TF structure shoulder as shown in Fig. 13(a).

The PF coil structures to place the 6 PF coils on the TF coil with a vertically symmetry to the machine mid-plane at 80 locations. All PF coil structures should absorb the difference in the thermal contraction between TF coil structures and PF coils during cool-down to cryogenic temperature, and endure the vertical and radial magnetic forces due to current charging. In order to satisfy these design requirements, the hinges or flexible plates are applied in the design.

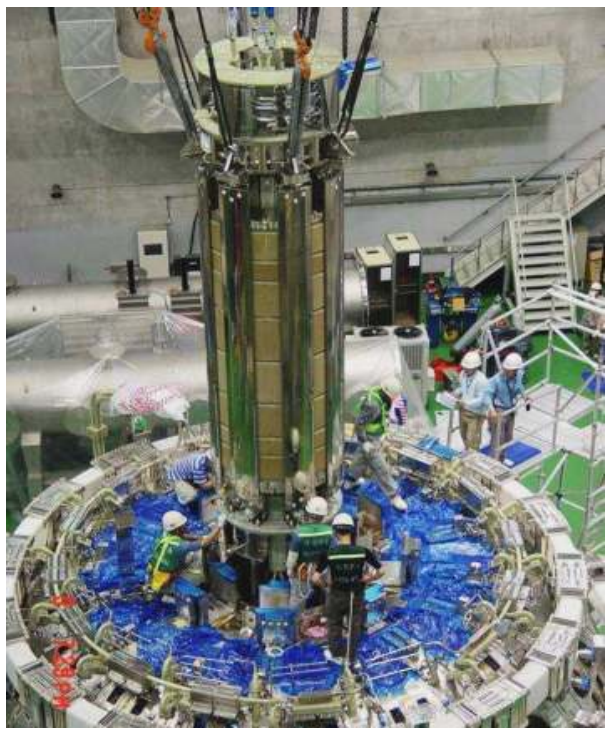

(a)

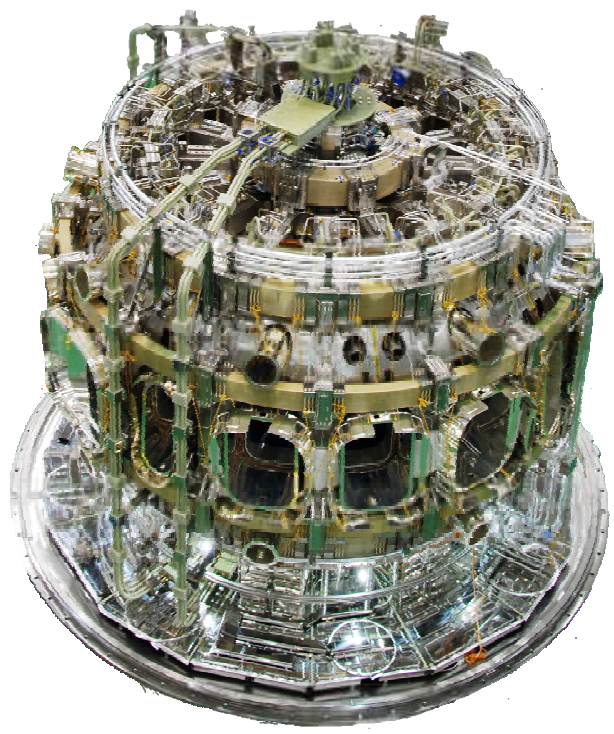

(b)

Fig. 13. Pictures of the KSTAR magnet system. The installation of the CS coil assembly into the center of the KSTAR device (a) and the completion of magnet assembly (b). 


\subsection{Magnet interfaces}

Magnet interface components are to supply electric power and cryogen and to monitor the operational status. Figure 13(b) shows the whole magnet system after installation of whole magnet system and its interface components.

SC buslines, which is components to carry the current from the cryostat boundary to the coil terminal joints, are made of $\mathrm{NbTi} \mathrm{CICC}$ with circular cross section to allow bending in any angle. Each busline was bended before installation according to the 3-dimensional assembly drawing and was insulated by wrapping with pre-pregnant glass-fiber and Kapton film. Two types of joints are installed between magnet and buslines, one is lap type joints which are installed at 136 locations and the other type is strand-to-strand joint which are installed at TF coil only (Park, Y.M. et al., 2009).

Current lead system is an interface component to deliver the large current from the power supply at room temperature to the superconducting magnet at the cryogenic temperature. KSTAR requires 7 pairs of PF leads having the current carrying capacity up to $25 \mathrm{kA}$ for more than $350 \mathrm{~s}$ and 2 pairs of TF leads having the current capacity over $17.5 \mathrm{kA}$ for steady state. Usually the heat load on the current lead is major portion of the heat load on the magnet system. So there are lots of researches to reduce the heat load of the current lead. In KSTAR, heat load reduction was achieved by replacing the copper conductor in the current lead material with brass conductor due to the low thermal conduction.

For the cooling of the magnet system and its interface, a cryogenic facility was constructed with a cooling capacity of $9 \mathrm{~kW}$ at $4.5 \mathrm{~K}$ equivalent. The cryogenic facility consists of gas management and compress station at room temperature, cold box to cool-down the cryogen, and helium distribution box to match the heat load in KSTAR. Figure 14 shows the process flow diagram of the KSTAR cryo-facility. The cryogenic helium is supplied to the magnet system in three phases. Supercritical helium is supplied to the all SC coils and magnet structures at $4.5 \mathrm{~K}, 5.5$ bar with mass flow rate of $600 \mathrm{~g} / \mathrm{s}$, liquid helium into current lead at $4.2 \mathrm{~K}, 1.3$ bar, and gaseous helium into thermal shield at about $55 \mathrm{~K}, 18$ bar. (Chang, H.S. et al., 2008; Kim, Y.S. et al., 2009). A thermal damper system to moderate the pulsed heat from PF magnet consists of several heat exchangers immersed in the liquid helium bath and several supercritical helium circulators.

In the magnet operation with large stored energy, normal regions arising in the superconducting coil can lead to permanent damage due to excessive heating. Reliable quench detection and protection is very important for the safe operation of the superconducting magnets. A total of 83 quench voltage detectors are installed and operated independently to detect quenches in the TF and PF coil systems (Chu, Y. et al., 2009). The quench voltage detection system of the KSTAR TF coils uses a conventional balanced bridge method detecting and comparing the voltage signal across each two TF coils with balanced inductance. For the fail-safe operation and to anticipate the malfunction of the detector, two detectors monitor the same section constantly in a simultaneous manner. Most of the self-inductance of each module could be compensated easily. There is some amount of non-linear voltage at low current due to Incoloy 908 ferromagnetic material in the $\mathrm{Nb}_{3} \mathrm{Sn}$ superconductors. When PF coil is operated together, the induced voltage is detected for about $100 \mathrm{~ms}$ due to the coupling of the inductance between TF and PF coils. Generally, the holding time was set to prevent the false signal 
from the voltage spike to trigger the interlock. As the TF QDS holding time is set to be $2 \mathrm{~s}$, the voltage noise due to blip operation was therefore not a problem The PF current abrupt change which is called as the blip operation during the short time span is necessary for making the loop voltages in the toroidal direction and initiating the plasma current. Hence, the noises of the quench detection system should be carefully analyzed and compensated below the proper levels. Two quench detectors were used for detecting the resistive voltage drop across the winding. The primary one uses the co-wound voltage sensing cable, which traces the surface of the CICC closely. If the magnetic coupling The PF current abrupt change which is called as the blip operation during the short time span is necessary for making the loop voltages in the toroidal direction and initiating the plasma current. Hence, the noises of the quench detection system should be carefully analyzed and compensated below the proper levels. Two quench detectors were used for detecting the resistive voltage drop across the winding. The primary one uses the cowound voltage sensing cable, which traces the surface of the CICC closely. If the magnetic coupling between the coil and the co-wound tape is sufficiently strong, the measured voltage at the co-wound voltage sensor can eliminate the most part of the inductive voltages in a coil. A conductive fabric tape was selected as a co-wound voltage sensing cable. The secondary one is the most commonly used method as shown. However the inductive voltage is detected in both conventional and co-wound sensors due to the field profile in each coil. By adding the differential comparator to subtract unbalanced signals in PF coils, most of the inductive voltage signal could be expelled as shown in the Fig. 15. Beside of the noise handling scheme, the quench detection holding time is introduced. That is, if the measured voltage stays above the threshold voltage over the predefined holding time, then the quench interlock is activated and the magnet energies are dumped into external dump resistors.

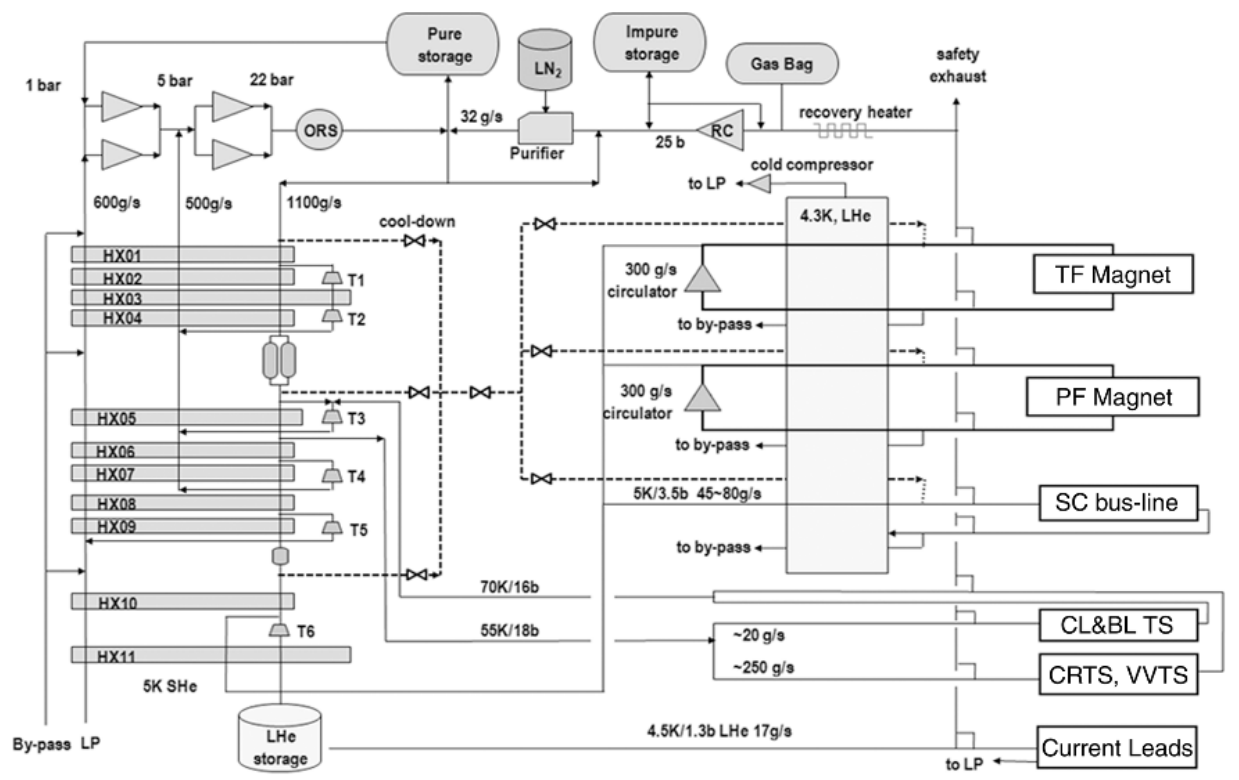

Fig. 14. Process flow diagram of the $9 \mathrm{~kW}$ cryo-facility to cool the KSTAR magnet system. 


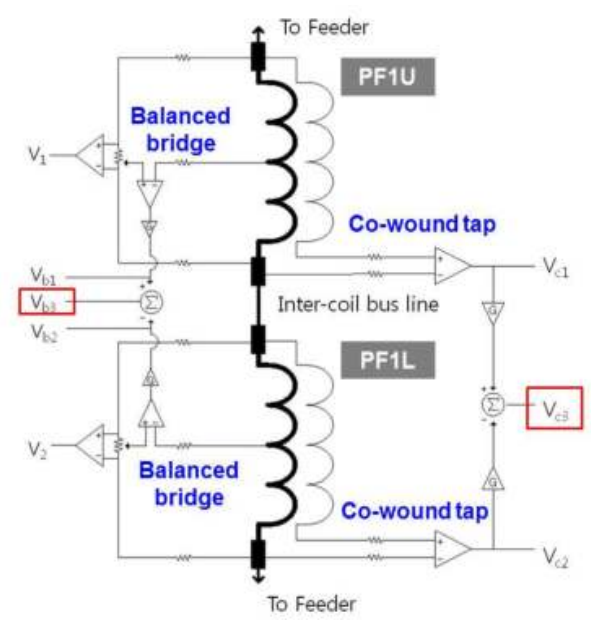

(a)

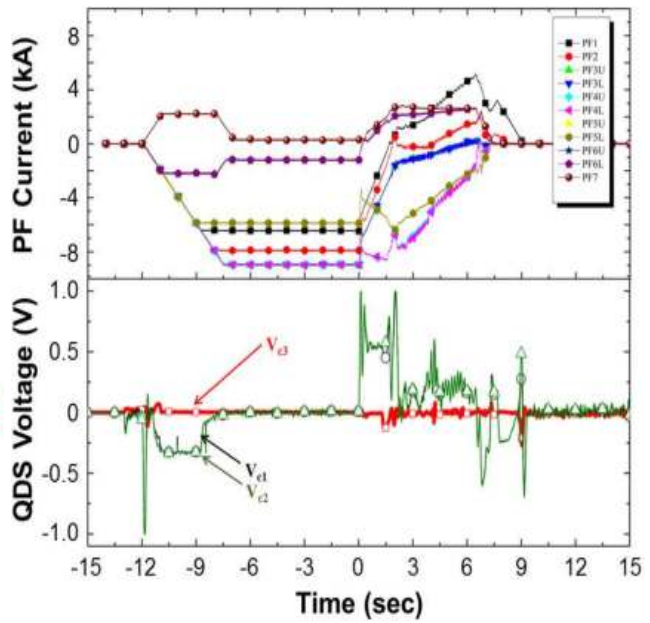

(b)

Fig. 15. Quench detection of KSTAR PF magnets. Quench detection circuit of the PF1 by balanced bridge and co-wound voltage tap (a), and comparison of the inductive voltage signals on the quench detection sensors during the regular PF coil operation (shot \#5199). Most of the inductive signal is cancelled at Vc3 signal lines. (b)

\section{Integrated commissioning of the magnet system in fusion device}

The operation of the superconducting fusion device could be classified into two phases, the integrated commissioning phase to inspect the quality of each component and to reduce unexpected risk occurrences and the normal operation phase to achieve the mission of the fusion device by the integrated operation of all system. There were several cases that the occurrence of damage or problem in the superconducting magnet system during its commissioning or initial operation made delay or prohibit the normal operation in superconducting fusion device or particle accelerator. The commissioning and the initial operation for the first plasma in the KSTAR device have been accomplished successfully without any severe failure preventing the device operation and plasma experiments. All the superconducting magnets operated in stable without quench for long-time dc operation and with synchronized pulse operation by the plasma control system . The first plasma target in the range of $100 \mathrm{kA}$ was achieved by assisted startup using an $84 \mathrm{GHz}$ electron cyclotron resonance heating (ECH) system and real-time feedback control (Oh, Y.K. et al., 2009). Figure 16 shows KSTAR device and the overall sequence of the KSTAR commissioning and the first plasma operation and the picture of control room during the commissioning. The commissioning of the KSTAR magnet system is classified into several steps: (i) inspection at room temperature after tokamak assembly, (ii) inspection during and after magnet cooldown, and (iii) stability assessment under operation condition of static or pulsed operation of magnet system. 


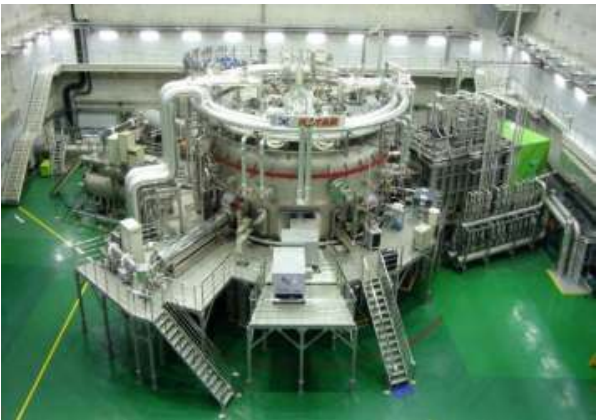

(a)

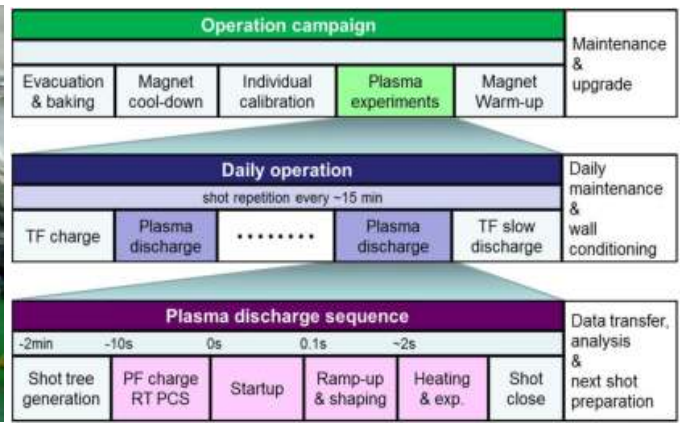

(b)

Fig. 16. Bird-eye view of the KSTAR device in during the 2010 operation (a), and the operation sequence of the plasma experiments $(\mathrm{b})$.

\subsection{Inspection at room temperature}

After completion of the KSTAR device assembly, a detailed inspection of each component was followed before the cooling down of the magnet system. The major inspection activities at room temperature are leak detection, electric insulation check, and magnetic field survey.

The leak detection is one of the critical activities in the superconducting magnet system. Although most of gas except helium are condensed on the magnet surface after the magnet cool-down, so the leak from the helium circulation line should be identified and repaired for the stable magnet cool-down and long-time operation for several month. The careful inspection of the leak from the magnet cooling lines is conducted by pressurizing the magnet cooling line with helium up to about 20 bar. The leak from the magnet system in KSTAR is not so high and could be repaired well. It is due to the tight quality control of each component before its installation in KSTAR. Usually most of the leaks come from the joint or welding point between different materials, and electrical breaker is the components of high leak possibility due to the connection of stainless steel tube to Ceramic insulator or GFRP insulator. So the leak inspection was conducted of ach electric breakers under high pressure helium after the several tens of thermal cycles from room temperature and liquid nitrogen temperature. To ensure the integrity of insulation of the superconducting system after all sub-systems were completely installed, the dc HIPOT test was carried out up to $10 \mathrm{kV}$ in each coil to diagnose the coil insulation before the cool-down. Conclusively, the insulation resistances of all coils were more than $100 \mathrm{M} \Omega$ which is the same criterion for the individual coil (Park, K.R. et al., 2009).

The magnetic field distribution in the vacuum vessel is measured after a low current less than $100 \mathrm{~A}$ is applied to each coil at the room temperature environment and compared with the calculated data. When the TF current is $100 \mathrm{~A}$, the B-field at the plasma center is approximately 100 gauss, and the B-field distribution is consistent with the calculated data although there was some discrepancy of the field detection close to the vacuum vessel inboard surface. There was a large discrepancy between measurements and calculations for the PF coils as shown in Fig. 17 (Yonekawa, H. et al., 2009). For instance, PF7 measurements at all the radial positions were approximately 30\% lower than the calculated values 
dismissing Incoloy 908. On the other hand, the PF1 discrepancy gradually increased from $3 \%$ to $36 \%$ as the measurement point approached the VV inside. The PF coils appeared to be shielded by some magnetic component surrounding the VV as their magnetic field was reduced in the VV whereas the TF coils seemed to be embedded in some magnetic material as their magnetic field rose suddenly at the VV inside close to the TF's windings. Magnet system cool-down was launched after passing the all required room temperature inspection for magnet system and other components.

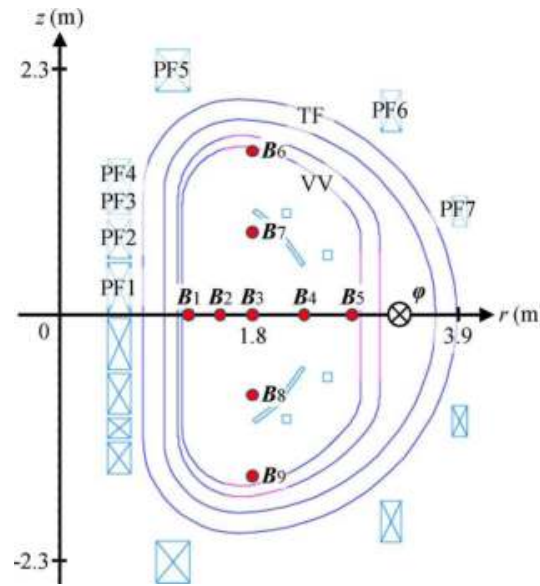

(a)

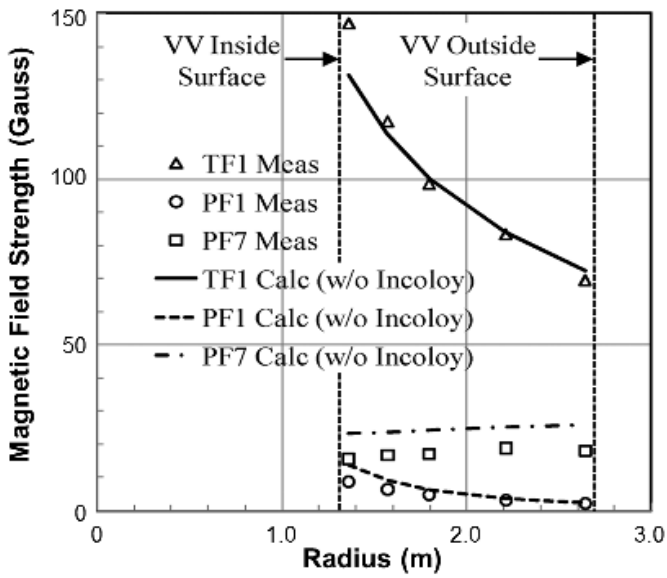

(b)

Fig. 17. The positions of the hall proves to measure the field profile in vacuum vessel (a), and the measured field strength at five radial positions according to the TF, PF1 or PF7 coil current charging up to $100 \mathrm{~A}(\mathrm{~b})$.

\subsection{Inspection during and after cool-down}

The total cold mass is about 300 tons. In order to cool-down this massive structure, the $9 \mathrm{~kW}$ helium refrigerators, the helium distribution valve box and in-cryostat cooling piping were installed. The cool-down period was about 23 days as shown in Fig. 18 (Kim, Y.S. et al, 2009). The major parameters such as the vacuum, the temperature, and the mass flow rate, were carefully checked during the cool-down. The structural behavior was also monitored because the different thermal shrinkage between the structurally connected bodies may give harmful effects on the structural integrity. The maximum difference of the temperature distribution inside the cryostat was set to be $50 \mathrm{~K}$, which is the value obtained from the experience in many large scale superconducting magnet applications. This criterion is not applied to the thermal shield because the thermal shield is an independent structure without any structural connection with the superconducting magnet system. As the much possibility of the cold leak exists, the residual gas inside the cryostat was continuously analyzed. The superconducting to normal transitions of the KSTAR magnet system were observed during the cool-down. As expected, the TF coil and the PF1-5 coils showed the transition around 18 $\mathrm{K}$. The measured RRR values were about 200 which satisfied the design value of more than 100. The PF6-7 and bus lines which are made of NbTi superconductor showed the transition around $9 \mathrm{~K}$ with RRR of about 100. 


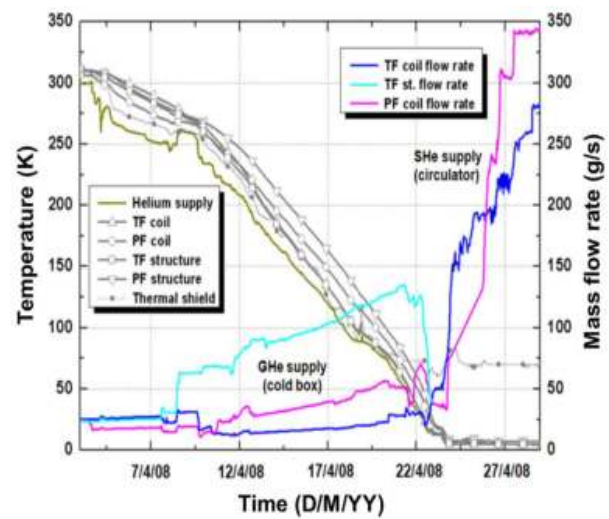

(a)

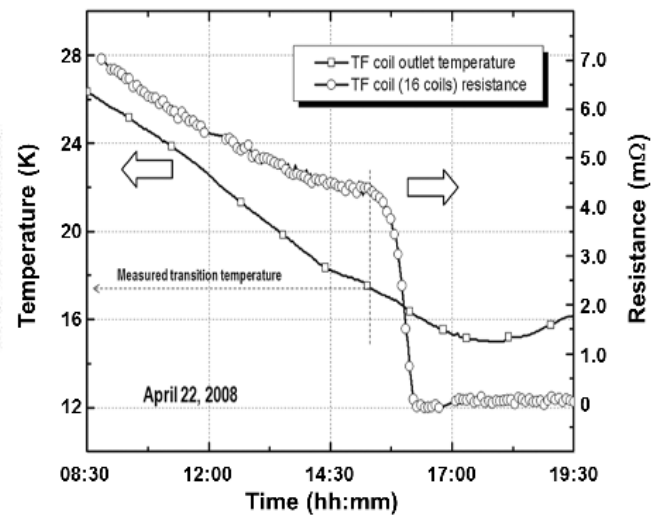

(b)

Fig. 18. The cool down characteristics of the magnet system. The change of overall mass flow rate of helium (a), and phase transition to superconductor at around $18 \mathrm{~K}(\mathrm{~b})$.

After finishing the cool-down, the HIPOT test was carried out up to $6 \mathrm{kV}$ for the final insulation check. As the operating currents were lower than the designed ones for all the coils in the first operation, the maximum possible voltage generation is less than $2.5 \mathrm{kV}$ between coil terminals (Park, K.R. et al., 2009). Therefore, the insulation test voltage of $6 \mathrm{kV}$ was considered to be sufficient for ensuring the insulation integrity.

Before the high current operation, it is mandatory to check the electrical joints for high currents. The designed resistance value is less than $5 \mathrm{n} \Omega$ per one lap joint. As the voltage was measured across the bus line which has the 3-4 lap joints, the averaged joint resistance was used to validate the joint resistances. The joint resistances were measured by V-I characteristic curve by scanning the current in the range of $\pm 900 \mathrm{~A}$. The resistance was obtained by the slope of the V-I curve. The measured joint resistance is less than $2.5 \mathrm{n} \Omega$ per joint and it satisfied the design value of less than $5 \mathrm{n} \Omega$ (Park, Y.M. et al., 2009).

\subsection{Inspection under the high current operation}

The objectives of inspection of the superconducting magnet under the high current operation are to check operational stability of magnets at high current operation conditions and to check the controllability of the coil currents and magnetic field profile for plasma discharges and confinement. The TF system was tested by increasing the current level in steps. The thermo-hydraulic and magnetic parameters were measured for the operating conditions. Figure 19(a) shows that TF magnet operated stable $30 \mathrm{kA}$ for more than 5 hours with the temperature rising less than $0.1 \mathrm{~K}$ during the current charge and discharge periods. The quench detection system also operated reliably. During the current charging and discharging time, the detected signal was less than $25 \mathrm{mV}$ and well below the trigger condition of $50 \mathrm{mV}$ and $2 \mathrm{~s}$ (Chu, Y. et al., 2009). 


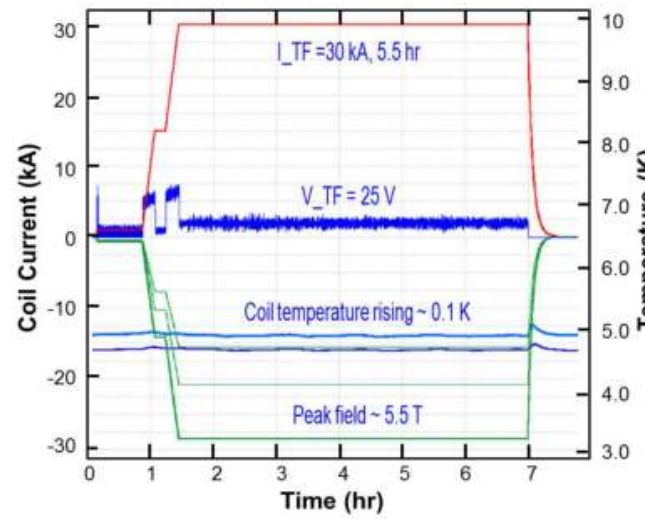

(a)

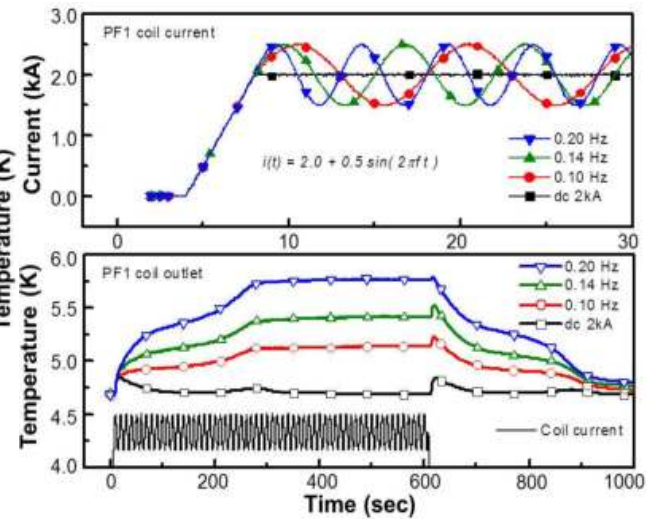

(b)

Fig. 19. The operational characteristic of the magnets. Stable operation of TF magnet at 30 $\mathrm{kA}$ over 5.5 hours with temperature rising of about $0.1 \mathrm{~K}(\mathrm{a})$, and ac loss measurement of PF1 coil by applying sinusoidal current waveform up to $600 \mathrm{~s} \mathrm{(b).}$

For KSTAR operation at currents up to $2 \mathrm{MA}$ and long pulses up to $300 \mathrm{~s}$, the ac losses of PF magnets can be a very important factor in deciding the operational capability. Precise measurements of the ac losses of the PF magnet system in KSTAR are difficult due to the limited number of sensors installed in KSTAR. AC loss was measured at the current waveforms of the typical single pulse waveform and of long pulse sinusoidal waveforms which were adopted in the KSTAR CS model coil experiments (Oh, Y.K. et al., 2009). Figure 19(b) shows the current waveform for ac loss measurement of the PF1 coil. The applied current was dc biased $2 \mathrm{kA}$ and sinusoidal ac current with amplitude of $0.5 \mathrm{kA}$ for $600 \mathrm{~s}$ according to changing the frequency from 0.1 to $0.2 \mathrm{~Hz}$. The figure shows that thermal parameters reached a steady-state condition after $350 \mathrm{~s}$. The coupling loss of PF1 showed different results according to the waveforms (Lee, H.J. et al., 2010; Oh, D.K. et al., 2010). The coupling loss time constant, $n \tau$ of PF1 measured by the single trapezoidal waveform was about $62.5 \mathrm{~ms}$ at the initial operation time and reduced to about $50 \mathrm{~ms}$ after two months operation. It could be expected that the cyclic electromagnetic force applied to the strands tends to increase the inter-strand contact resistance, and resulted in the reduced coupling loss. When compared with sinusoidal method, the measured time constant was about $35 \mathrm{~ms}$. The difference of the $\mathrm{n} \tau$ could come from the non-linear current control at low current less than $500 \mathrm{~A}$. Another interesting result is that the coupling time constant of the PF6 coil is also about 33ms even though it has NbTi conductor. These results could come from the adoption of chrome coating on all three kinds of strands, $\mathrm{Nb}_{3} \mathrm{Sn}, \mathrm{NbTi}$, and copper. These results show that the KSTAR construction has advantages for various operational capabilities especially high speed PF6 coil operation as in the first plasma operation. The superconducting magnet commissioning was completed without any severe problems in spite of the fact that individual cool-down tests were not conducted prior to assembly. 


\section{Plasma experiments and magnet operation}

\subsection{Plasma confinement and experiments}

After the successful integrated commissioning in 2008, KSTAR device has been operated to meet the project mission to establish a scientific and technological basis for the attractive fusion reactor. The operating performance of the device was upgraded every year. In the first campaign, the first plasma was achieved with a plasma current over $100 \mathrm{kA}$ just after the integrated commissioning in 2008 (Oh, Y.K. et al., 2009). In the second and third campaigns, by the reliable control of the plasma current and shape, high performance confinement (H-mode) plasma could be achieved at the plasma current over $500 \mathrm{kA}$ as shown in the Fig. 20. In the $4^{\text {th }}$ campaign, the plasma current reached up to $1 \mathrm{MA}$ and various researches could be conducted such as suppression of the edge local mode (ELM).

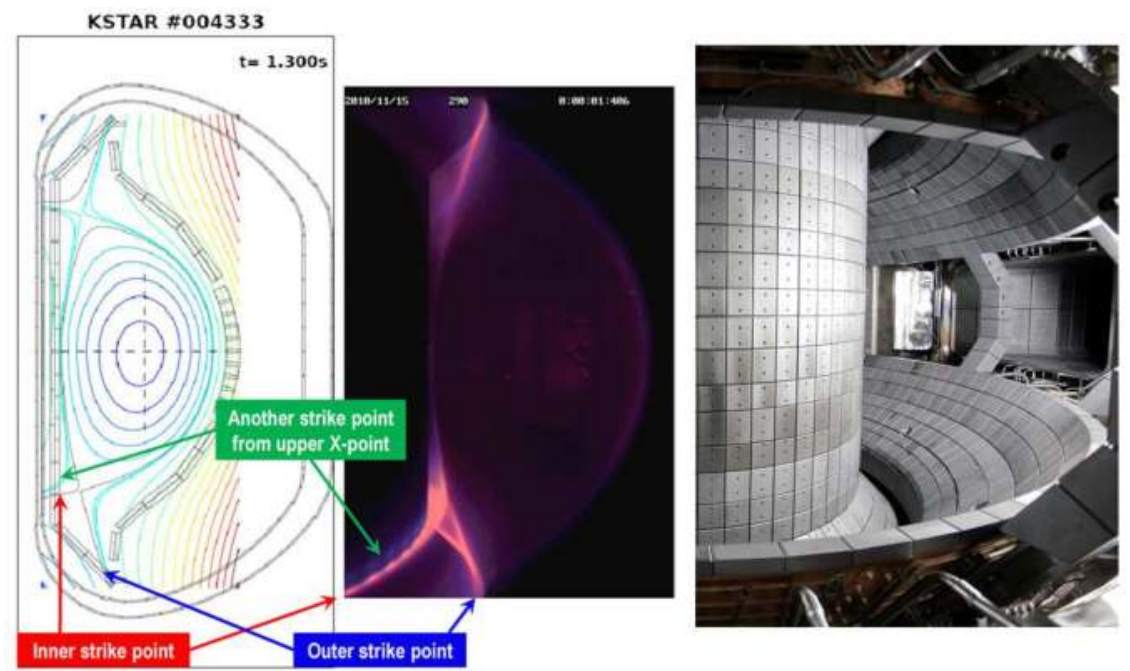

Fig. 20. High performance plasma confinement (H-mode) achievement in KSTAR. Plasma profile reconstruction using EFIT, CCD visual image, and the picture of in-vessel components.

Usually the plasma operation could be classified into several phases; plasma startup to generate a plasma current up to about $100 \mathrm{kA}$, feedback plasma control for the current ramp up and shaping, plasma heating and experimental research under various operational modes, and plasma current ramp-down or disruption. The plasma current and shape are controlled by the plasma control system which is a feedback control loop with the diagnostics sensors and PF magnet power supplies (Hahn, S.H. et al., 2009).

The basic criteria for plasma startup are formation of the field null and the loop voltage to drive the plasma current rise (Leuer, J.A. et al., 2010). However the startup in the KSTAR was complicated due to the nonlinear magnetic behavior associated with the Incoloy 908 jacket material used in the construction of the $\mathrm{Nb}_{3} \mathrm{Sn}$ superconductors. The field distortion was investigated by scanning the field profile using the hall probe array and monitoring the e-beam trajectories according to the TF and PF coil current (England, A.C. et al., 2011). The 
field deformation due to the ferromagnetic effect was deliberately compensated by including the control of field gradients since the field gradients determined the positional stability of the plasma current channel. As a consequence, plasma start-up became much more robust against the deviation from the expected plasma initial ramp-up. And the field null formation was intentionally delayed until the toroidal electric field reached a sufficient level to make inductive breakdown of the neutral gas. By doing so, we could obtain better breakdown conditions with the same level of loop voltage. Hence purely ohmic discharges were routinely achieved under various toroidal magnetic fields (Kim, J. et al., 2011).

ELMy H-mode discharges have been observed from the third campaign with combined auxiliary heating of neutral beam injection $\left(\mathrm{P}_{\mathrm{NBI}} \leq 1.4 \mathrm{MW}\right)$ and electron cyclotron resonant heating $\left(\mathrm{P}_{\mathrm{ECRH}} \leq 0.2 \mathrm{MW}\right)$ in a relatively low density regime. The $\mathrm{L}-\mathrm{H}$ transitions occurred typically right after the end of the plasma current (Ip) ramp-up to $0.6 \mathrm{MA}$ and after the fast shaping to a highly elongated double-null (DN) divertor configuration (Yoon, S.W. et al., 2011). The ELM is an evidence of the H-mode confinement but it is an issue to be prevented or mitigated to protect the plasma facing components or divertor from the damage by the energetic particles flux. The ELM is one of the critical issues in the ITER device. By applying three-dimensional field on the plasma, ELM suppression or mitigation could be achieved in the $4^{\text {th }}$ campaign. As shown in Fig. 21. KSTAR is targeted to achieve the reliable plasma control at the plasma current of $2 \mathrm{MA}$, in-inductive steady-state operation up to $300 \mathrm{~s}$, and plasma heating using by $28 \mathrm{MW}$ auxiliary heating systems.
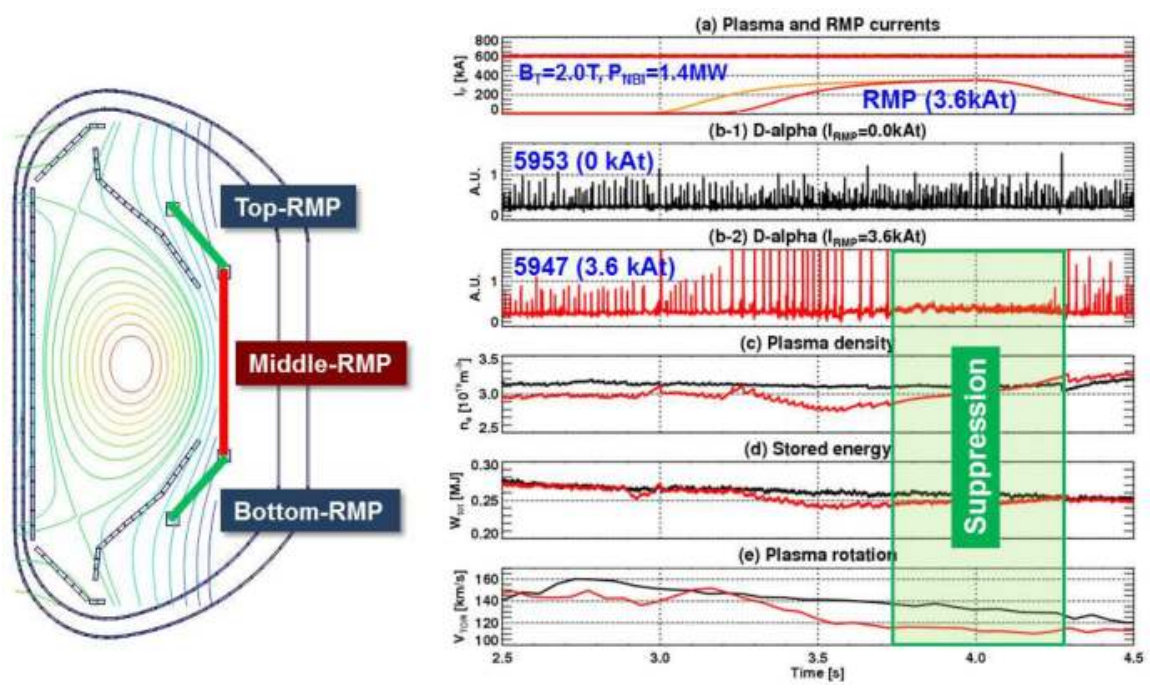

Fig. 21. Edge localized mode (ELM) occurrence in H-mode plasma and its suppression by applying 3D field ( $\mathrm{n}=1 \mathrm{RMP})$ using in-vessel control coils.

\subsection{Cryogenic stability of magnet system}

In the KSTAR operation, the TF magnet has been operated up to the designed operating current of $35.2 \mathrm{kA}$ in stable with temperature rising of $0.1 \mathrm{~K}$. The toroidal field was $3.5 \mathrm{~T}$ at plasma center and peak field inside conductor was 7.2 T with temperature margin of about 4 
K. The superconductor of the KSTAR TF magnet has an operational capability of toroidal field up to $5.0 \mathrm{~T}$ with a temperature margin of $1.1 \mathrm{~K}$ as shown in Table 4.

\begin{tabular}{l|c|c|c|c}
\hline Parameters & \multicolumn{2}{|c|}{ Designed operation } & \multicolumn{2}{c}{ Extended operation } \\
\hline Toroidal field, $\mathrm{B}_{0}[\mathrm{~T}]$ & 3.5 & 3.5 & $\mathbf{4 . 5}$ & $\mathbf{5 . 0}$ \\
Peak field, $\mathrm{B}_{\text {peak }}[\mathrm{T})$ & 7.2 & 7.2 & 9.3 & 10.3 \\
Coil current, $\mathrm{I}_{\mathrm{TF}}[\mathrm{kA}]$ & 35.2 & 35.2 & 45.3 & 50.3 \\
Strain on $\mathrm{Nb}_{3} \mathrm{Sn}[\%]$ & $\mathbf{0 . 7}$ & $\mathbf{0 . 3}$ & $\mathbf{0 . 7}$ & $\mathbf{0 . 3}$ \\
Current sharing Temp, $\mathrm{T}_{\mathrm{CS}}[\mathrm{K}]$ & 9.16 & 10.5 & 5.86 & 5.85 \\
Temp. margin, $\mathrm{T}_{\text {margin }}[\mathrm{K}]$ & 4.4 & 5.7 & 1.1 & 1.1 \\
\hline
\end{tabular}

Table 4. Estimation of the temperature margin of the TF magnet at designed condition and extended performance conditions.

The PF magnets are designed to be operated for the plasma current startup and ramp up to 2 MA inductively, and plasma of 1 MA current has been achieved in 2011 operation in spite of the limited electric power supply. The designed current of $2 \mathrm{MA}$ is expected to be achieved after the completion of a motor-generator system. Nominal operational scenario of the PF magnets is started from the initial magnetization to store a maximum flux in each magnet and is followed by a synchronized fast flux swing for the plasma startup and finally is continued by the fast feedback control of plasma current, shape, and position. When the PF magnet operated in pulse, large amount of pulsed heat is generated in the magnet due to the ac loss which is deeply related with conductor design and the field swing rate.

The cryogenic system of the PF magnet has been designed to be operated under the pulsed heat load by adopting the thermal damper concept. A cryogenic circulator will be operated in static to supply the supercritical helium in to PF magnets with a total mass flow rate of about $300 \mathrm{~g} / \mathrm{s}$ with pressure drop of about 2 bar. The transient heat from the PF magnet is extracted by the heat exchangers which are immersed at the liquid helium bath as shown in Fig. 22(a). Most of the PF shot was operated stably within the However the operation range of the circulator. However in some scenario with fast current changing scenario, a large thermal load causes abrupt flow and pressure increase of the helium. The supply and return pressure of the circulator are increased simultaneously with shot. The mass flow rate in the PF 1 magnet was maintained the value of zero for several seconds as shown in Fig. 22(b). And the operation point of the cryogenic circulator moved into the unstable zone and transiently (Lee, H.J. et al., 2011; park, Y.M. et al., 2010). Although the PF magnets are made of with low as loss conductor, additional efforts are required for the stable operation of the cryogenic circulator as well as magnet system itself.

One of the approaches is optimizing the PF magnet operation scenario sharing the burden of ac loss with other magnets. There were similar approaches in the conventional tokamaks to reduce the burden on central solenoid by solenoid-free startup in DIII-D (Leuer, J.A. et al., 2010) or by coaxial helicity injection in NSTX (Raman, R. et al., 2001). Another way is to limit the maximum field change rate within certain range because the ac loss is proportion to the square of the field change rate. The modification the cryogenic circuits could be considered to clamp the cryogenic parameter fluctuation in the cryogenic circulator under the large thermal load in PF magnet. It could maximize the operation capability of PF magnet without increasing overall capacity of the cryo-facility. 


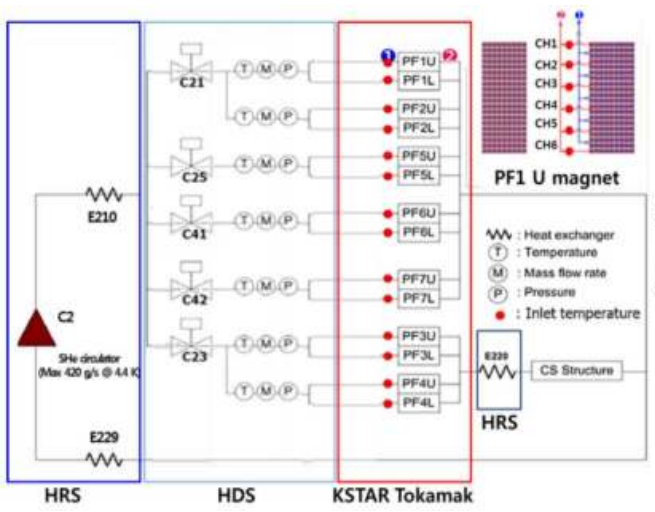

(a)

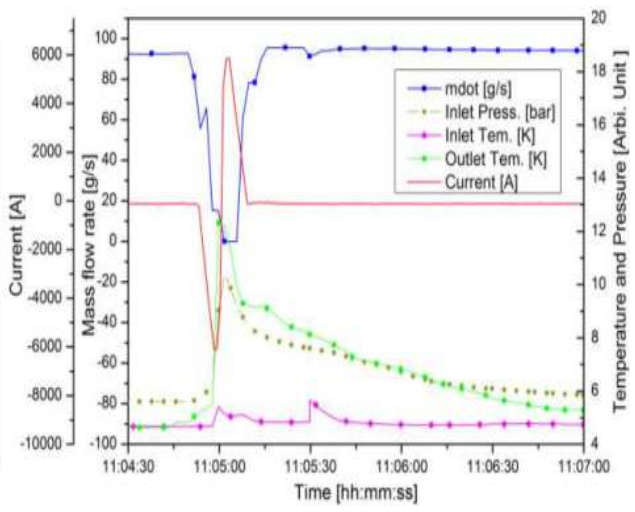

(b)

Fig. 22. Flow diagram of the PF magnet cooling circuits (a), and flow reversal occurrence in some extreme operation of the PF magnet at bipolar operation with $10 \mathrm{kA} / \mathrm{s} \mathrm{(b)}$

\subsection{Other issues in superconductor application to fusion devices}

For superconductor application to the future fusion reactor, more R\&D activities are required to develop the conductor designs having stable operation capability under the extreme environments such as higher magnetic field and higher current density operation. However there are some technical issues which hinder the fabrication of the large current $\mathrm{Nb}_{3} \mathrm{Sn}$ conductor for ITER.

One of the issues is irreversible degradation in $\mathrm{Nb}_{3} \mathrm{Sn}$ CICC (Bruzzone, P. 2010), usually the longitudinal strain applied to the $\mathrm{Nb}_{3} \mathrm{Sn}$ makes the decrease the allowable limit of the operation current density. The longitudinal strain mainly comes when the CICC was cooled down from the heat treatment temperature about $600 \mathrm{C}$ to operating temperature of $5 \mathrm{~K}$ due to the difference of coefficient of thermal expansion. And it is regarded as reversible phenomena. Another load applied on the conductor is the transverse load by the Lorentz force from the conductor current and self-field. In many sample test of the ITER conductor showed the degradation of the performance of $\mathrm{Nb}_{3} \mathrm{Sn}$ CICC by the number of load cycle. The possible interpretation of the degradation is plastic deformation of the superconductor filament by the bending of strand when the cyclic transverse load is applied. The cycled load applied on the $\mathrm{Nb}_{3} \mathrm{Sn}$ conductor is helpful for the ac loss reduction but reduction of the dc performance.

ITER TF magnet is designed with a concept of insertion of circular conductor in the premachined groove in the radial plate to prevent the accumulation of the transverse force on the conductor. But the conductor length changed after heat treatment mainly due to the residual stress during the jacket compaction and coil winding. So it is not easy to control the gap between TF CICC and the grove in the radial plate. 
Those kinds of issues will be explored according to the operation of the present superconducting fusion devices.

\section{Conclusion}

The application of the superconductor to the magnetic confinement fusion devices is inevitable to achieve a steady-state plasma confinement under the high field environment. There has been a lot of progress in the superconducting magnet technology in fusion application. Initially it was only to the static field magnets by using the Rutherford-type conductor cooled in a liquid helium bath, but now it is applied to the pulsed field magnets also by using the CICC type conductor which is cooled with forced flow supercritical helium and is robust for the large electromagnetic and high voltage conditions. The KSTAR device has been constructed using the fully superconducting magnets which are up-to-date in technologies.

The representative outstanding technologies of the magnet systems in the KSTAR devices are as follows; high performance $\mathrm{Nb}_{3} \mathrm{Sn}$ conductor development to be used commonly in TF and PF magnets, reliable chrome coating on strand surface to reduce the ac coupling loss, long-length CICC production up to $1.8 \mathrm{~km}$ by tube-mill welding process of jacket, high reliability in the leak detection and repair welding of CICC, continuous magnet winding without internal joint by numerical shape control, successful heat treatment of Nb3Sn magnet with Incoloy908 jacket without failure, turn insulation taping and full penetration VPI technology, new method of TF magnet installation by rotating each one along the surface of the vacuum vessel, applying pre-compression on the central solenoids structure by heating the structure and wedge adjustment, and stable operation and protection of the magnet system. The successful construction and operation of the KSTAR device using the $\mathrm{Nb}_{3} \mathrm{Sn}$ superconductor brought a great positive impact in the worldwide fusion reactor preparation including the international experimental fusion device, ITER.

There are several remained issues in the superconducting magnet application in the world-wide superconductor application into the fusion reactors, especially for the large scale fusion reactors. Large fluctuations of the thermo-hydraulic parameters in cryofacility are mainly due to the ac loss in the PF magnet limit the operational capability of the PF magnets. And the performance degradation of the $\mathrm{Nb}_{3} \mathrm{Sn}$ conductor was found in the development for the ITER magnet conductor such as allowable current density decrease under the large amount of the transverse force In the CICC and the current sharing temperature is also decreased after the large number of operation cycle. Those kinds of issues will be explored according to the operation of the present superconducting fusion devices. New optimum operational scenarios of the PF magnets should be developed also to reduce the ac loss and to maximize the static operation range.

\section{Acknowledgement}

The authors appreciate all the participants and researchers who contributed to the construction, operation and experiments of the KSTAR device, especially to the 
superconducting magnets system development. This work was supported by the Korean Ministry of Education, Science and Technology under the KSTAR project.

\section{References}

Ahn, H.J.; et al. (2002). Engineering design status of the KSTAR TF coil structure. IEEE Trans. on Applied Superconductivity, Vol. 12, pp. 492-495

Bak, J.S.; et al. (2006). Status of the KSTAR tokamak construction. Fusion Engineering and Design, Vol. 81, pp. 2315-2324

Bruzzone, P. (2010). Superconductors for fusion: Achievements, open issues, roadmap to future. Physica C, Vol. 470, pp. 1734-1739

Chang, H.S.; et al. (2008). The on-site status of the KSTAR helium refrigeration system. Advances in Cryogenic Engineering, Vol. 53, pp. 437-444

Choi, C.H.; et al. (2002). Electromagnetic loads on the KSTAR magnet system. IEEE Trans. on Applied Superconductivity, Vol. 12, pp. 534-537

$\mathrm{Chu}$, Y.; et al. (2009). Quench detection based on voltage measurement for the KSTAR superconducting coils. IEEE Trans. on Applied Superconductivity, Vol. 19, pp. 15651568

England, A.C.; et al. (2011). Tokamak field error measurements with an electron beam in KSTAR. Fusion Engineering and Design, Vol. 86, pp. 20-26

Hahn, S.H.; et al. (2009). Plasma control system for "Day-one" operation of KSTAR tokamak. Fusion Engineering and Design, Vol. 84, pp. 867-874

Kim, J.; et al. (2011). Stable plasma start-up in the KSTAR device under various discharge conditions. Nuclear Fusion, Vol. 51, p. 083034

Kim, K.; et al. (2005). Status of the KSTAR superconducting magnet system development. Nuclear Fusion, Vol.45, pp. 783-789

Kim, K.; et al. (2006). Status of the K STAR Project. Journal of Cryogenic Society of Japan, Vol. 41, pp. $184-192$

Kim, Y.S.; et al. (2009). First commissioning results of the KSTAR cryogenic system. IEEE Trans. on Applied Superconductivity, Vol. 19, pp. 1577-1581

Lee, G.S.; et al. (2001). Design and construction of the KSTAR tokamak. Nuclear Fusion, Vol. 41, pp. $1515-1523$

Lee, H.J.; et al. (2010). The ac loss measurement of the KSTAR PF1 coils during the first commissioning. IEEE Trans. on Applied Superconductivity, Vol. 20, pp. 551-555

Lee, H.J.; et al. (2011). Analysis of the reversal flow phenomenon of supercritical helium due to ac losses in KSTAR PF magnets at low current. IEEE Trans. on Applied Superconductivity, Vol. 21, pp. 2012-2015

Lee, S.; et al. (2006). Ac loss characteristics of the KSTAR CSMC estimated by pulse test. IEEE Trans. on Applied Superconductivity, Vol. 16, pp. 771-774

Leuer, J.A.; et al. (2010). Plasma startup design of fully superconducting tokamak EAST and KSTAR with implications for ITER. IEEE Trans. on Plasma Science, Vol. 38, pp. 333340

Leuer, J.A.; et al. (2011). Solenoid-free startup experiments in DIII-D. Nuclear Fusion, Vol. 51, p. 063038 
Lim, B.S.; et al. (2005). Jacketing and reapir of the KSTAR CICC. IEEE Trans. on Applied Superconductivity, Vol. 15, pp. 1415-1418

Mitchell, N. (2003). Summary, assessment and implications of the ITER model coil test results. Fusion Engineering and Design, Vol. 66-68, pp.971-993

Oh, D.K.; et al. (2004). Design and thermo-hydraulic analysis of upgraded PUMA system for the development of a test facility of superconducting CICC. IEEE Trans. on Applied Superconductivity, Vol. 19, pp. 1557-1560

Oh, D.K.; et al. (2010). Development of numerical model of KSTAR PF conductor and magnet for the analyses of AC loss on the results of KSTAR PF magnet test run. IEEE Trans. on Applied Superconductivity, Vol. 20, pp. 2164-2167

Oh, Y.K.; et al. (2002). Engineering design status of the KSTAR central solenoid structure. IEEE Trans. on Applied Superconductivity, Vol. 12, pp. 615-618

Oh, Y.K.; et al. (2004). Cool-down and current test results of the KSTAR prototype TF coil. Advances in Cryogenic Engineering, Vol. 49, pp. 241-248

Oh, Y.K.; et al. (2005). Status of the KSTAR Tokamak Construction and Assembly. Journal of the Korean Physics Society, Vol. 49, pp. s1-s6

Oh, Y.K.; et al. (2008). Completion of the KSTAR construction and its role as ITER pilot device. Fusion Engineering and Design, Vol. 83, pp. 804-808

Oh, Y.K.; et al. (2009). Commissioning and initial operation of KSTAR superconducting tokamak. Fusion Engineering and Design, Vol. 84, pp. 344-350

Park, K.R.; et al. (2005). Status of the KSTAR PF6 and PF7 coil development. IEEE Trans. on Applied Superconductivity, Vol. 15, pp. 1375-1378

Park, K.R.; et al. (2009). Qualification test results of the KSTAR superconducting coils from the construction to the commissioning steps. IEEE Trans. on Applied Superconductivity, Vol. 19, pp. 1561-1564

Park, Y.M.; et al. (2009). Construction and commissioning of the KSTAR current feeder system. IEEE Trans. on Applied Superconductivity, Vol. 19, pp. 1587-1591

Park, Y.M.; et al. (2010). Analysis of the helium behavior due to AC losses in the KSTAR superconducting coils. IEEE Trans. on Applied Superconductivity, Vol. 20, pp. 530-533

Raman, R.; et al. (2001). Non-inductive current generation in NSTX using coaxial helicity injection. Nuclear Fusion, Vol. 41, p. 1081-1086

Sa, J.W.; et al. (2002). Detailed evaluation of insulation stress in the KSTAR central solenoid. IEEE Trans. on Applied Superconductivity, Vol. 12, pp. 619-622

Wu, S.; et al. (2007). An overview of the EAST project. Fusion Engineering and Design, Vol. 82, pp. $463-471$

Yang, H.L.; et al. (2006). KSTAR assembly. Proceeding of IAEA FEC 2006 conference (October, 2006), http://www-naweb.iaea.org/napc/physics/fec/fec2006/html/node339. htm, FT/2-2

Yonegawa, H.; et al. (2009). KSTAR magnetic field measurement during the commissioning and remnant field evaluation. IEEE Trans. on Applied Superconductivity, Vol. 19, pp. 1573-1576

Yoon, S.W.; et al. (2011). Characteristics of the first H-mode discharge in KSTAR. Nuclear Fusion, Vol. 51, p. 113009 
Yoshida, K.; et al. (2008). Conceptual design of superconducting magnet system for JT-60SA. IEEE Trans. on Applied Superconductivity, Vol. 18, pp. 441-446 


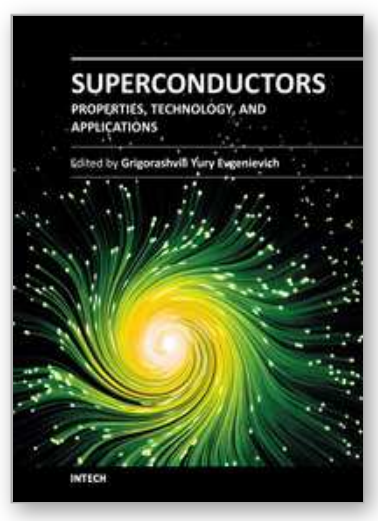

\author{
Superconductors - Properties, Technology, and Applications \\ Edited by Dr. Yury Grigorashvili
}

ISBN 978-953-51-0545-9

Hard cover, 436 pages

Publisher InTech

Published online 20, April, 2012

Published in print edition April, 2012

Book "Superconductors - Properties, Technology, and Applications" gives an overview of major problems encountered in this field of study. Most of the material presented in this book is the result of authors' own research that has been carried out over a long period of time. A number of chapters thoroughly describe the fundamental electrical and structural properties of the superconductors as well as the methods researching those properties. The sourcebook comprehensively covers the advanced techniques and concepts of superconductivity. It's intended for a wide range of readers.

\title{
How to reference
}

In order to correctly reference this scholarly work, feel free to copy and paste the following:

Yeong-Kook Oh, Keeman Kim, Kap-Rai Park and Young-Min Park (2012). Superconductor Application to the Magnetic Fusion Devices for the Steady-State Plasma Confinement Achievement, Superconductors Properties, Technology, and Applications, Dr. Yury Grigorashvili (Ed.), ISBN: 978-953-51-0545-9, InTech, Available from: http://www.intechopen.com/books/superconductors-properties-technology-andapplications/superconductor-application-to-the-magnetic-fusion-devices-for-the-steady-state-plasmaconfinement-ac

\section{INTECH}

open science | open minds

\section{InTech Europe}

University Campus STeP Ri

Slavka Krautzeka 83/A

51000 Rijeka, Croatia

Phone: +385 (51) 770447

Fax: +385 (51) 686166

www.intechopen.com

\section{InTech China}

Unit 405, Office Block, Hotel Equatorial Shanghai

No.65, Yan An Road (West), Shanghai, 200040, China 中国上海市延安西路65号上海国际贵都大饭店办公楼405单元

Phone: +86-21-62489820

Fax: $+86-21-62489821$ 
(C) 2012 The Author(s). Licensee IntechOpen. This is an open access article distributed under the terms of the Creative Commons Attribution 3.0 License, which permits unrestricted use, distribution, and reproduction in any medium, provided the original work is properly cited. 